Review

\title{
Arachnid toxinology in Australia: from clinical toxicology to potential applications
}

\section{Graham M. Nicholson ${ }^{a, *}$, Andis Graudins ${ }^{\mathrm{b}}$, Harry I. Wilson ${ }^{\mathrm{a}}$, Michelle Little $^{\mathrm{a}}$, Kevin W. Broady}

${ }^{a}$ Neurotoxin Research Group, Department of Heath Sciences, University of Technology, Sydney, City Campus, Broadway, NSW, 2007, Australia

${ }^{b}$ Division of Clinical \& Experimental Toxicology, Prince of Wales Hospital, Randwick NSW 2031 and Faculty of Medicine, University of New South Wales, Kensington NSW 2052 Australia

${ }^{c}$ Department of Cell \& Molecular Biology, University of Technology, Sydney, Gore Hill Campus, St Leonards, NSW, 2065, Australia

* Corresponding author. Associate Professor Graham Nicholson, PhD

Neurotoxin Research Group

Department of Heath Sciences

University of Technology, Sydney

PO Box 123

Broadway, NSW, 2007

Australia

Tel.: +61-2-9514-2230; fax: +61-2-9514-2228

E-mail address: Graham.Nicholson@uts.edu.au (G.M. Nicholson) 


\section{Abstract}

The unique geographic isolation of Australia has resulted in the evolution of a distinctive range of Australian arachnid fauna. Through the pioneering work of a number of Australian arachnologists, toxinologists and clinicians, the taxonomy and distribution of new species, the effective clinical treatment of envenomation, and the isolation and characterisation of the many distinctive neurotoxins, has been achieved. In particular, work has focused on several Australian arachnids, including red-back and funnel-web spiders, paralysis ticks and buthid scorpions that contain neurotoxins capable of causing death or serious systemic envenomation. In the case of spiders, species-specific antivenoms have been developed to treat envenomed patients that show considerable cross-reactivity. Both in vitro and clinical case studies have shown they are particularly efficacious in the treatment of envenomation by spiders even from unrelated families. Despite their notorious reputation, the high selectivity and potency of a unique range of toxins from the venom of Australian arachnids will make them invaluable molecular tools for studies of neurotransmitter release and vesicle exocytosis as well as ion channel structure and function. The venoms of funnel-web spiders, and more recently Australian scorpions, have also provided a previously untapped rich source of insect-selective neurotoxins for the future development of biopesticides and the characterisation of previously unvalidated insecticide targets. This review provides an historical viewpoint of the work of many toxinologists to isolate and characterise just some of the toxins produced by such a unique group of arachnids and examines the potential applications of these novel peptides.

Keywords: Australian spiders, $\alpha$-Latrotoxin, Atracotoxins, Missulenatoxins, Australian scorpions, Australian paralysis tick, Antivenom, bioinsecticide 
Abbreviations: Aah-II, mammalian-selective scorpion $\alpha$-toxin isolated from the venom of Androctonus australis hector; ACTX, atracotoxin isolated from spiders belonging to the sub-family Atracinae (Australian Funnel-web spiders - Hadronyche and Atrax species); $\delta$-ACTX, voltage-gated Na channel specific atracotoxins, $\kappa-A C T X$, insect-selective calcium-activated potassium channel blocking atracotoxins (formerly known as J-ACTX); $\omega$-ACTX, insect-selective voltage-gated Ca channel blocking atracotoxin; $\mu$-Aga, $\mu$-agatoxin from the American funnel-web spider Agelenopsis aperta; $\mathrm{BK}_{\mathrm{Ca}}$, large conductance calcium-activated potassium channel; Bv8, protein Bv8 from the yellowbellied toad Bombina variegata; CIRL, calcium-independent receptor for latrotoxin (also known as latrophilin 1); Cls, $\underline{\mathrm{CIRL}}$ and latrophilin receptors; HPLC, high-performance liquid chromatography; hPK, human prokineticin; HT, holocyclotoxin from the Australian paralysis tick Ixodes holocyclus; ICK, inhibitor cystine-knot; IgG, immunoglobulin G; IgM, immunoglobulin M; $\mathrm{LD}_{50}$, median lethal dose; $\alpha$-LTx, vertebrate-selective latrotoxin from the venom of the European widow spider Latrodectus tredecimguttatus; Lqh $\alpha \mathrm{IT}$, insect-selective scorpion $\alpha$-insect toxin isolated form the venom of Leiurus quinquestriatus hebraeus; MIT1, mamba intestinal toxin 1 from the black mamba snake Dendroaspis p. polylepis; MSTX, missulenatoxin isolated from mouse spiders of the genus Missulena; $\delta$-MSTX, voltage-gated sodium channel specific missulenatoxin; NMR, nuclear magnetic resonance; s.c., subcutaneous; SDS-PAGE, sodium dodecyl sulphate-polyacrylamide gel electrophoresis; TTX, tetrodotoxin; VGCC, voltage-gated calcium channel; VGSC, voltage-gated sodium channel.

\section{Contents}

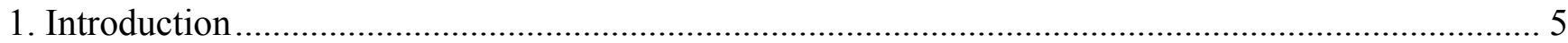

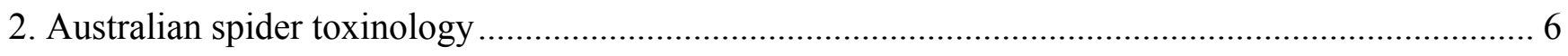

2.1. Australian spider envenomation: extent of the problem .................................................. 6

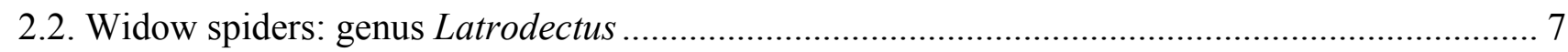

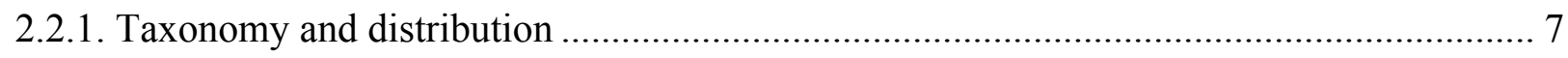


2.2.2. Latrodectism: clinical features of Latrodectus envenomation ........................................... 8

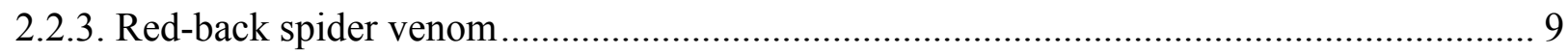

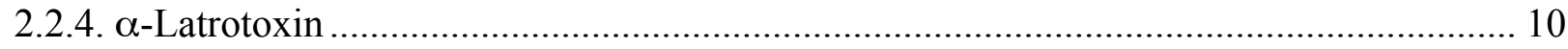

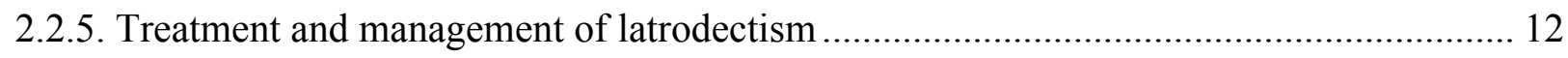

2.2.6. Antivenom cross-reactivity with other Latrodectus venoms ............................................ 13

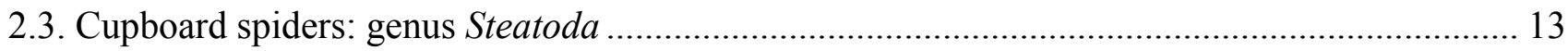

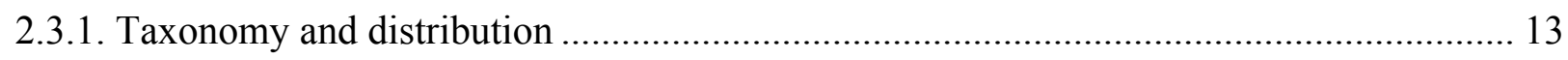

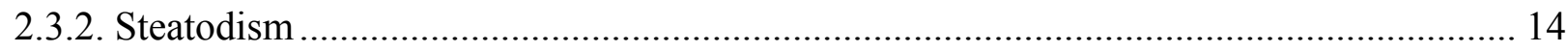

2.3.3. Characterisation of Steatoda venoms......................................................................... 14

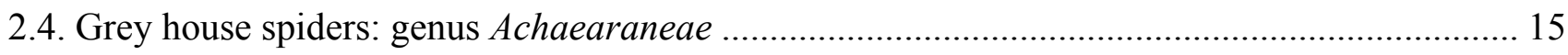

2.5 Australian funnel-web spiders: genera Atrax and Hadronyche …............................................ 15

2.5.1. Taxonomy and distribution ........................................................................................ 15

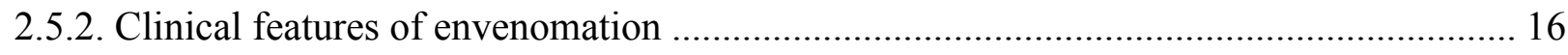

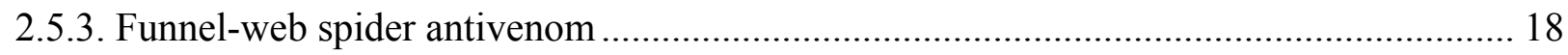

2.5.4. Natural inhibitors of funnel-web spider venom ............................................................ 19

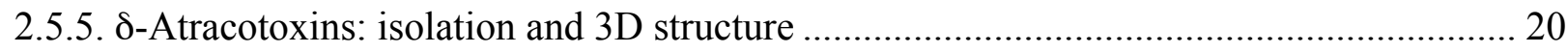

2.5.6. 8-Atracotoxins: target site and mode of action ................................................................ 22

2.5.6. $\omega$ - and $\kappa$-Atracotoxins: insecticidal neurotoxins............................................................. 24

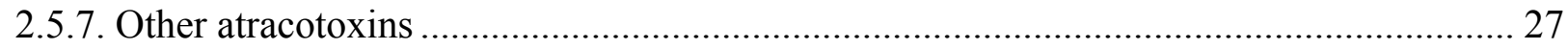

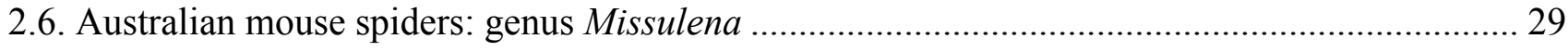

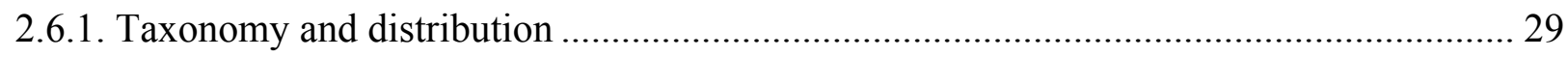

2.6.2. Clinical manifestations of mouse spider envenomation.................................................... 29

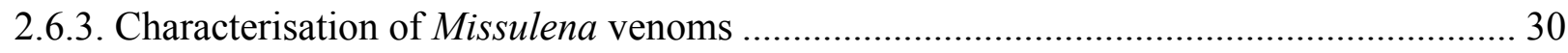

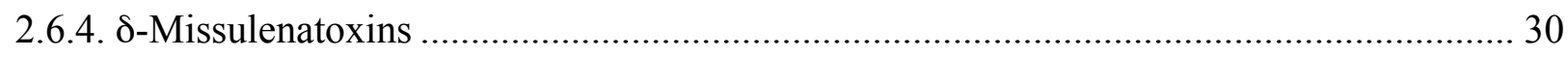

2.7. Necrotising arachnidism in Australia: fact or fiction? ............................................................. 31

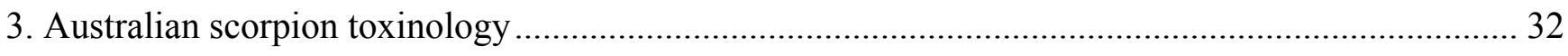

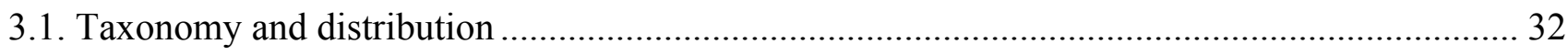

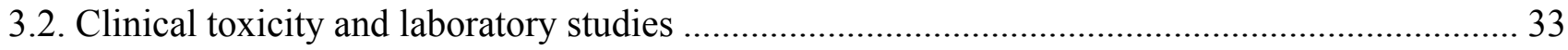

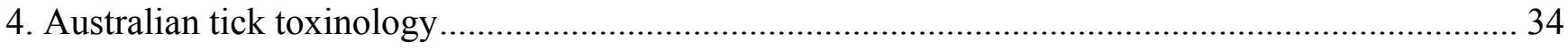

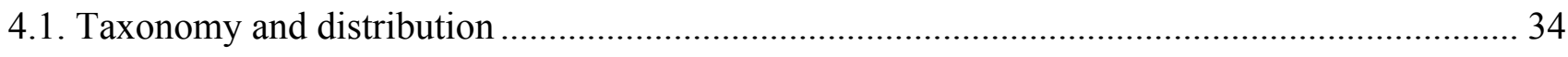

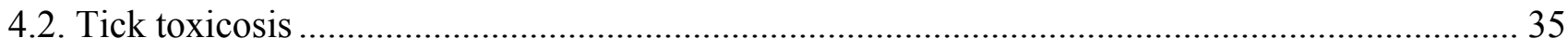

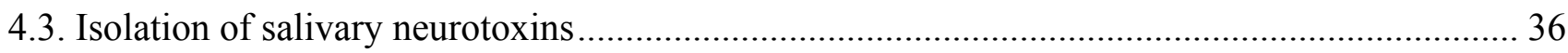


4.4. Mechanism of action of salivary neurotoxins

4.5. Antivenom

5. Conclusions, future directions and further applications. 38

Acknowledgements.

References

\section{Introduction}

Few, if any other groups of venomous animals conjure up the emotion of fear, the potential human medical risks, and the economic losses to companion and stock animals than members of the class Arachnida. Important venomous creatures in this class include the order Scorpionida (scorpions), order Araneae (spiders) and order Acarina (ticks) (Fig. 1A). Yet many of these creatures, particularly spiders and scorpions, present an immense combinatorial peptide library for the potential development of insecticides and pharmaceuticals which to date has gone largely untapped. Importantly, Australia represents a unique biological environment that supports distinctive species within these orders that continue to be the focus of toxinologists.

Figure 1 here

This review will concentrate primarily on Australian research investigating clinical features of envenomation and treatment, and the biochemistry and pharmacology of venoms from classes Araneae and Acarina. Despite the lack of mammalian activity of most species of Australian scorpions, and hence limited investigation, a cursory coverage is provided for completeness. Included in the review is the work of Australian researchers investigating the commercial application of these neurotoxins in the fields of pharmacology and neuroscience and the development of novel insecticides for the control of phytophagous pests and insect vectors of disease. 


\section{Australian spider toxinology}

Apart from insects, spiders represent one of the most successful terrestrial invertebrates with over 38,000 described species worldwide (Platnick, 1997). Spider venoms contain potent neurotoxins and other bioactive compounds, many of which are lethal to humans or selectively insecticidal. Many of these neurotoxins are highly potent and specifically target ion channels, receptors or other targets involved in important physiological functions (for extensive reviews of spider toxin structure and function see Escoubas et al., 2000; Nicholson and Graudins, 2002; Rash and Hodgson, 2002). Others are now being investigated for their possible use as bioinsecticidal agents for the control of insecticide-resistant pests (for reviews see King et al., 2002; Maggio et al., 2004; Tedford et al., 2004).

In Australia, spiders are the most widely distributed venomous creatures with a conservative

estimate of over 10,000 species in this country (Raven, 1988). However, there is a distinct lack of knowledge of the distribution and venom composition of the vast majority of these spiders. The most notable exceptions are the red-back (Latrodectus hasselti), funnel-web (Atrax and Hadronyche spp.) and to a lesser extent mouse spiders (Missulena spp.) and cupboard spiders (Steatoda spp.) (Fig. 2A-D). These contain potentially lethal primate and insecticidal neurotoxins and have become the focus of Australian spider toxinology research since the pioneering studies of Charles Kellaway, Alan Musgrave and Saul Weiner.

Figure 2 here

\subsection{Australian spider envenomation: extent of the problem}

The true incidence of spider bite, systemic envenomation and death resulting from spider bite in humans world-wide is unknown due the paucity of data from poisoning and envenomation cases in most regions, particularly definite bites from identified species. Nevertheless, in Australia there are about 4000-5000 calls each year for information about spider bites to the New South Wales Poisons Information Centre, the largest centre in the country. This is only eclipsed by paracetamol as the most 
frequent reason for inquiries (Kirby, 1998; Duggin et al., 2002). Unfortunately, data collection on the calls is extremely limited and the true incidence of spider bite in the general community is more than likely under-represented by these figures. Although most cases of spider bite result in minimal, if any, significant clinical consequences, in Australia there are a number of spider neurotoxins that may produce either serious systemic clinical envenomation syndromes or significant local reactions. The extent of this problem has been recently addressed by Geoff Isbister (Newcastle Mater Misericordiae Hospital, Newcastle) and Mike Gray (Australian Museum, Sydney) where a prospective study has investigated the types of spiders involved in envenomations in Australia, and the severity of any clinical effects (Isbister and Gray, 2002).

\subsection{Widow spiders: genus Latrodectus}

\subsubsection{Taxonomy and distribution}

Arguably the most clinically significant group of spiders worldwide and specifically in Australia are the widow or comb-footed spiders (Araneae: Araneomorphae: Theridiidae), mainly belonging to the genus Latrodectus. In Australia, medically important theridiid spiders are from three genera. These include the red-back spider (Latrodectus hasselti; Fig. 2A), cupboard spiders (Steatoda capensis and S. grossa; Fig. 2B) and to a much lesser extent Archaearaneae spp. Despite their potentially fatal bite, as is the case with the red-back spider, little is known about the true incidence of envenomation from theridiid spiders due to a lack of organised data collection in most regions of the world. In Australia, a gross estimate of over 5000 L. hasselti bites per year has been made (Isbister and White, 2004). Nevertheless, there is considerable geographic variation in the incidence of bites with far more in the temperate regions of Australia, particularly New South Wales, and far fewer in the colder south or tropical north (Sutherland and Trinca, 1978; Woo and Smart, 1999; Isbister et al., 2001; Isbister and Gray, 2002).

Figure 3 here 
Interestingly, Australian clinicians and scientists in the 1920's originally disagreed as to whether or not $L$. hasselti was to be considered dangerous. Several studies by the early Australian toxinologist Musgrave and others confirmed that L. hasselti bites were potentially lethal (Jackson, 1927; Cleland, 1932; Ingram and Musgrave, 1933). Indeed, clinically significant red-back spider envenomation requiring antivenom therapy occurs in around 20\% of cases (White, 1998). While the antivenom is very effective, latrodectism should still be regarded as potentially fatal with the most recent death attributable to L. hasselti occurring as recently as 1999 (as reported by Sutherland and Tibballs, 2001d). Although rarely fatal, envenomation by Latrodectus spp. may result in an incapacitating syndrome of severe local, regional, or systemic pain and autonomic features called 'latrodectism' which, if left untreated, may last for several days or weeks. Notwithstanding the frequency of bites by Australian red-back spiders there are only a few studies that clearly describe the clinical effects of $L$. hasselti (reviewed in Isbister and White, 2004).

\subsubsection{Latrodectism: clinical features of Latrodectus envenomation}

Specifically in Australia, clear clinical studies of the effects of the bite and effectiveness of antivenoms have been mainly carried out by four groups headed by Geoff Isbister (Newcastle Mater Misericordiae Hospital, Newcastle), Julian White (Women's and Children's Hospital, Adelaide) and George Jelinek (Sir Charles Gardiner Hospital, Perth) and Struan Sutherland (Commonwealth Serum Labratories, Melbourne). The syndrome of latrodectism may vary in severity depending on the species and size of the spider, the season, and the amount of venom injected but appears to be similar regardless of the geographic location of the spider (Maretic, 1983; Muller, 1993; Zukowski, 1993). Most commonly local pain, sweating, erythema, and piloerection are noted at the bite site within 1 hour. Clinical features may remain isolated to the site of the bite or less commonly progress to become regional or systemic. Regional features may be heralded by the development of lymphangitis towards regional lymph nodes that may be palpable and painful. Other regional features may include those seen 
at the bite site. Piloerection, sweating, and muscle fasciculation may be distributed throughout the bitten limb, in both limbs or in the contralateral limb only. The predominant feature of generalised latrodectism, however, is pain. Upper limb bites may result in pain predominantly to the face, neck, or chest, while bites to the lower limbs may produce abdominal and buttock pain (White et al., 1995). Patients may develop generalised diaphoresis, muscle pains, weakness, vomiting, tachycardia, hypertension, dyspnoea, and intermittent muscle twitching or tremor (Maretic, 1983; White et al., 1995). When severe envenomation occurs death may result but typically only in young infants or the very elderly. The natural progression of envenomation is a gradual diminution of symptoms and signs over several days to weeks although, uncommonly, features of envenomation may persist for months. A recent prospective study of red-back spider bites in Australia showed that the majority of bites cause significant effects with severe and persistent pain occurring in two thirds of bites, sufficiently severe to prevent the patient sleeping in almost a third of all cases (Isbister and Gray, 2003c).

\subsubsection{Red-back spider venom}

Original studies of $L$. hasselti venom were undertaken by Wiener who assayed venom toxicity and developed an antivenom in rabbits (Drummond and Wiener, 1956; Wiener, 1956a; b). While extensive research has been carried out on the venom and toxins of overseas species of Latrodectus (over 400 papers), surprisingly little research has been undertaken on the venom of the Australian red-back spider. Nevertheless, the venoms of all Latrodectus spp. are thought to contain similar toxic components. This claim is based on three significant observations. Firstly, envenomation resulting from the bite of any widow spider results in a similar clinical picture regardless of the species of spider (section 2.2.2). Secondly, widow spider antivenoms produced using the venoms of specific Latrodectus spp. reverse the effects of envenomation from other Latrodectus spiders both in experimental animal models and in the clinical setting (section 2.2.5). Lastly, recent extensive but incomplete sequencing of 
an $\alpha$-latrotoxin from the red-back spider shows high homology with $\alpha$-latrotoxin from the European widow spider (section 2.2.4).

\subsection{4. $\alpha$-Latrotoxin: from function to structure}

There have been many reviews of the structure and mechanisms of actions of $\alpha$-latrotoxin $(\alpha$-LTx) the $120 \mathrm{kDa}$ neurotoxin responsible for the clinical effects of widow spiders on nerve terminals (for reviews see Sudhof, 2001; Ushkaryov, 2002; Ushkaryov et al., 2004). Surprisingly, isolation and complete sequencing of the neurotoxin responsible for latrodectism has only been reported from the European widow spider L. tredecimguttatus and currently there are no published reports of identification of the neurotoxin from other overseas species. Nevertheless, the similar symptoms observed in clinical cases of red-back spider envenomation, together with cross-reactivity in Western blots using red-back antivenoms, and the prevention of toxicity by L. tredecimguttatus venom in mice studies all suggest that the neurotoxin is likely to be very similar (Daly et al., 2001; Graudins et al., 2001; Graudins et al., 2002a). Indeed, recent studies carried out by the authors indicate that, following partial sequencing of the gene encoding for $\alpha$-latrotoxin from $L$. hasselti, there is $95 \%$ homology in amino acid sequence between latrotoxins from different species and similar mechanisms of neurotoxicity of L. hasselti neurotoxins (Graudins et al., 2002b).

The overall action of $\alpha$-LTx or crude Latrodectus spider venom is to cause massive synaptic vesicle exocytosis from the presynaptic terminal (Sudhof, 2001; Ushkaryov, 2002; Ushkaryov et al., 2004). In brief, there appears to be four distinct steps: (a) $\alpha$-LTx binds with high affinity to one or both of its receptors localised close to the active zone in the presynaptic plasma membrane. The first of these protein receptors are the neurexins, a calcium-dependent family of single transmembrane domain neuron-specific cell-adhesion molecules. The second class of $\alpha$-LTx receptors are a calcium-independent receptor class called CLs (for CIRL and latrophilins) simultaneously described by 
two groups; (b) after binding with either CLs or neurexins, the entire N-terminal portion of $\alpha$-LTx then inserts into the presynaptic plasma membrane; (c) The toxin then forms divalent cation-dependent multimers in the membrane creating a nonselective cation channel, and (d) finally the toxin causes intracellular activation of exocytosis. In the final mechanism, $\alpha$-LTx has a dual mechanism of action to trigger vesicle exocytosis. In one mode, $\alpha$-LTx acts as a channel in the membrane that conducts calcium triggering a number of intracellular events as well as mediating release of neurotransmitter from the cytosol. In the second mode, $\alpha$-LTx directly stimulates exocytosis of small clear vesicles in a calcium-independent manner. Eventually the action of $\alpha$-LTx results in the depletion of synaptic vesicles, with vesicle endocytosis unable to compensate for the increased exocytosis. In summary, the current hypothesis is that $\alpha$-LTx interferes with a process that normally inhibits vesicle fusion in the absence of calcium.

More recently the oligomerisation and three-dimensional structure of $\alpha$-LTx has been determined. Initial reports identified that $\alpha$-LTx, under normal conditions, exists as a dimer but can tetramerise in the presence of divalent cations or amphipathic molecules. Indeed it is now believed that the tetramer most likely represents the active form of $\alpha$-LTx (Ashton et al., 2000). The three dimensional structure of the $\alpha$-LTx monomer has been determined using cryo electron microscopy and found to consist of three main domains: a N-terminal wing connected to a large L-shaped body which, in turn, is attached to a C-terminal head region via a short thin neck forming a very angled molecule. The $\alpha$-LTx tetramer complex consists of four monomers arranged in a four-bladed propeller formation surrounding a central pore with a minimum diameter of $10 \AA$. Therefore upon binding of the hydrophobic base of the tetramer to cell-surface receptors the central pore allows the passage of divalent, and certain monovalent, cations (Orlova et al., 2000) but also causes leakage of the transmitter pool that is present in the nerve terminal (Ashton et al., 2000; Ashton et al., 2001). Research into the precise mechanism of action is ongoing and is likely to result in a major advancement in our 
understanding of the intracellular signaling transduction machinery, the biochemical differences and locations of the readily releasable and depot pools of synaptic vesicles, and how the release processes at various synapses differs.

\subsubsection{Treatment and management of latrodectism}

The availability of various spider antivenoms and their use has been recently reviewed (Isbister et al., 2003a; Nicholson and Graudins, 2003). It is commonly held that antivenom therapy is the most effective treatment for the symptoms and signs of latrodectism particularly in Australia where a species-specific antivenom is available (Wiener, 1956b; 1961b; Sutherland and Trinca, 1978; Clark et al., 1992). Patients receiving antivenom therapy are more likely to be discharged home directly from emergency departments and have much shorter hospital stays than those receiving supportive measures alone (Clark et al., 1992). Despite this there is some unwillingness to use widow spider antivenoms in some countries, particularly North America, because of a perceived high risk of allergic reactions to crotalid snake antivenoms (Dart and McNally, 2001) and a single fatal case following black widow antivenoms (Clark et al., 1992). Yet there is little likelihood of early allergic reactions with most widow spider antivenoms, based on studies in the United States and Australia (Sutherland and Trinca, 1978; Clark, 2001). In Australia, a high percentage of red-back spider bites cause severe systemic effects (Sutherland and Trinca, 1978; Isbister and Gray, 2003c; Trethewy et al., 2003) such that antivenom is warranted in up to two thirds of these cases (Isbister and White, 2004). However, there is ongoing controversy as to the route of administration with increasing data indicating that the intramuscular route is far less useful than previously believed (Isbister, 2002; Isbister and Gray, 2003c). This issue is currently being addressed by a randomised controlled trial conducted by Geoff Isbister.

Specific antivenoms raised against the venoms of various Latrodectus spp. have been developed in many regions of the world. In Australia a species-specific antivenom was originally raised in rabbits 
to the venom of the red-back spider (Wiener, 1956b), more recently the antivenom is now marketed as an equine $\mathrm{F}(\mathrm{ab})_{2}$ fragment. This is the most commonly used antivenom in the country (Sutherland and Trinca, 1978; White, 1998; Ho et al., 1999). Nevertheless, there are large regions around the world where no local antivenom is available. These include Central Asia, the Middle East, northern Africa and Southeast Asia, and also Europe. This has led several researchers to investigate the possibility of using antivenoms from other regions or countries to treat latrodectism.

\subsubsection{Antivenom cross-reactivity with other Latrodectus venoms}

It has been noted that species-specific antivenoms, such as red-back spider antivenom, are capable of treating envenomation from more than one kind of widow spider. Indeed clinical observations of antivenom use around the world and in vivo studies in mice suggest that it may be possible to use antivenom raised to the venom of related widow spiders from other continents to treat widow and related theridiid spider envenomation (Daly et al., 2001; Graudins et al., 2001; Graudins et al., 2002a). These observations suggest that all widow spider antivenoms may be capable of reversing clinical envenomation by any other Latrodectus spp. worldwide. This is supported by the observation that $L$. hasselti antivenom can neutralise the toxicity of $\alpha$-LTx derived from L. tredecimguttatus venom (Graudins et al., 2001). This is the main neurotoxin thought to be present in all medically important Latrodectus spp. and possibly other theridiid spider venoms (see section 2.3.2). In particular, the low incidence of side-effects noted with trypsin digested red-back spider antivenom make this possible candidate as a 'universal' antivenom (Daly et al., 2001; Graudins et al., 2001).

\subsection{Cupboard spiders: genus Steatoda}

\subsubsection{Taxonomy and distribution}

Australian researchers have recently focused on the 'cupboard, 'brown house', or 'false widow' spider (Fig. 2B), descriptive terms used to encompass various species of Steatoda (Araneae: 
Araneomorphae: Theridiidae). This is a group of comb-footed spiders related to widow spiders. Indeed they are often mistaken for widow spiders given their similar size and appearance. They are found worldwide and are endemic to most continents including Australia (Fig. 3B).

\subsubsection{Steatodism}

In general, bites from Steatoda spp. result in minor local symptoms not requiring any specific intervention. In Australia, however, two species, S. grossa and S. capensis, have been implicated in a small number of cases of systemic envenomation in humans, also called 'steatodism' (South et al., 1998; Winkel et al., 2000; Graudins et al., 2002a; Isbister and Gray, 2003a). Indeed the most number of reported envenomations appear to be from Australia (Isbister and Gray, 2003a). The envenomation syndrome observed in more severe cases is similar to that of latrodectism except that it is typically less acute and there is an absence of local and regional diaphoresis (Isbister and Gray, 2003a). Indeed, it has recently been speculated that a number of cases of latrodectism where the spider was not identified may in fact be severe cases of steatodism (Isbister and Gray, 2003a). These clinical findings add further support to in vitro observations of an $\alpha$-LTx-like effect by Steatoda spp. venoms in the isolated chick biventer cervicis nerve-muscle preparation (Graudins et al., 2002a). It is therefore not surprising that red-back spider antivenom has been successfully administered in several cases of systemic steatodism in Australia with resolution of all features of envenomation (South et al., 1998; Winkel et al., 2000; Graudins et al., 2002a; Isbister and Gray, 2003a).

\subsubsection{Characterisation of Steatoda venoms}

To date there has only been limited attempts to isolate the active neurotoxin from Steatoda spp. venoms given its apparent labile nature following reversed-phase HPLC separation of venom (Graudins et al., 2002a). However, S. grossa and S. capensis venoms show similar abilities to cause transmitter release in a variety of isolated preparations (Korszniak and Story, 1994; Graudins et al., 2002a); A. 
Graudins and G.M. Nicholson, unpublished data). In addition, S. grossa and S. capensis venoms are immunogenically similar to Latrodectus venoms in western blots using red-back antivenom They also appear chromatographically similar using size exclusion followed by anion exchange chromatography (Graudins et al., 2002a; A. Graudins and G.M. Nicholson, unpublished data). This supports the clinical observation that red-back antivenom is efficacious in the treatment of steatodism and provides further evidence to suggest that Steatoda venoms contain an $\alpha$-LTx-like neurotoxin.

\subsection{Grey house spiders: genus Achaearaneae}

In Australia, the only other spider from the family Theridiidae of any medical importance is the grey house spider Achaearaneae trepidariorum, an introduced but widely distributed cosmopolitan species. Like Steatoda spp., it is similar in shape and appearance to red-back spiders, but the abdomen is smaller and it is dark brown or grey in colour, lacking the characteristic red markings on the dorsal or ventral surfaces of Latrodectus spp. It may also have variably shaped chevrons on its dorsal surface and the legs often are marked with rings. Bites from these spiders have been reported to cause similar symptoms of persistent pain as bites from red-back and cupboard spiders. However, in the five reported envenomations no systemic effects were noted (Isbister and Gray, 2003b). To date, no investigation of the venom of this spider has been undertaken.

\subsection{Australian funnel-web spiders: genera Atrax and Hadronyche}

\subsubsection{Taxonomy and distribution}

Australian funnel-web spider venom arguably represents the most toxic spider venom known to affect humans. This is based on clinical reports and lethal dose studies in animals (Wiener, 1957; Gray and Sutherland, 1978).

Funnel-web spiders are a diverse group of large aggressive, nocturnal spiders (Araneae: Mygalomorphae: Hexathelidae: Atracinae) that are classified into two genera, Atrax and Hadronyche, 
comprised of at least 40 species, based on morphological and electrophoretic data (Fig. 2C) (Gray, 1988). Australian funnel-web spiders, not to be confused with the unrelated American funnel-web spider (Agelenopsis aperta), are found primarily along the eastern seaboard of Australia from southeastern Queensland to Tasmania and in a small pocket in South Australia (Fig. 3C). The Atracinae sub-family, containing the genera Atrax and Hadronyche, is continually undergoing taxonomic revisions as descriptions and distributions continual evolve. This is due to the untiring efforts of Mike Gray (Australian Museum, Sydney) and Robert Raven (Queensland Museum, Brisbane).

\subsubsection{Clinical features of envenomation}

When significant systemic envenomation occurs a unique syndrome develops which can cause death within 15 minutes. Between 1927 and the introduction of an antivenom for clinical use in 1980 fourteen deaths have been reported in the medical literature (Sutherland, 1980). All deaths were caused by bites from the Sydney funnel-web spider A. robustus, and in all cases where sex could be determined, it was found to be the male of the species (Fig. 2C). This is most likely due to the proximity of this spider to the populated areas of the Sydney basin than an indication of differences in potency between species of funnel-web given that nine other Atrax and Hadronyche spp. contain neurotoxins active on mammals in vitro (Graudins et al., 2002c). Moreover, other species of funnel-web spider from varied locations in NSW and Queensland have caused serious systemic illness in humans. They include male $H$. versuta (Blue Mountains funnel-web), H. formidabilis (Northern tree dwelling funnel-web), H. cerberea (Southern tree dwelling funnel-web) and H. infensa (Toowoomba funnel-web) (Dieckmann et al., 1989; Harrington et al., 1999; Miller et al., 2000). Despite all fatalities being associated with the bite of male $A$. robustus, this sex difference in venom toxicity is not apparent in most other Atrax and Hadronyche spp. venoms studied to date (Graudins et al., 2002c).

Despite having a deadly reputation, bites from this spider are an uncommon phenomenon being around $1 \%$ of all spider bites (Isbister and Gray, 2002). Indeed only between 5-10 severe 
envenomations requiring antivenom are believed to occur in Australia each year (White et al., 1995). In addition, there is clear evidence that these spiders do not release venom or deliver ineffective 'dry' bites in most cases, with typically less than $10-25 \%$ of bites leading to severe envenomation requiring antivenom treatment (Harrington et al., 1999; Isbister and Gray, 2002; Isbister and Gray, 2004). Despite of the availability of an effective antivenom, the severity and rapidity of systemic envenomation dictate that bites from this spider should be considered as potentially life-threatening.

The envenomation syndromes observed following bites by different species of funnel-web spiders are identical (Dieckmann et al., 1989; Harrington et al., 1999; Miller et al., 2000). In support of this clinical evidence, the authors have also determined that venoms from ten Atrax and Hadronyche spp. cause identical effects on neuromuscular transmission in the chick biventer cervicis preparation (Graudins et al., 2002c). Clinical features of envenomation in primates involve initial local features including muscle fasciculation, sweating, and piloerection. The bite is initially very painful and systemic envenomation may develop extremely rapidly and has been reported as quickly as 10 minutes following a bite (White et al., 1995; Sutherland and Tibballs, 2001a). Early symptoms of systemic envenomation include perioral tingling, tongue and facial muscle fasciculation, nausea, vomiting, profuse sweating, salivation, lachrymation, and dyspnoea (for a summary of several clinical cases see Sutherland and Tibballs, 2001a). Patients may rapidly develop confusion, agitation, and coma associated with marked hypertension, metabolic acidosis, raised intracranial pressure, mydriasis, generalised muscle fasciculation, and non-cardiogenic pulmonary oedema (Torda et al., 1980). Children may deteriorate rapidly and death may result in 1 to 2 hours if left untreated (Sutherland and Tibballs, 2001a). In adults, untreated envenomation may result in marked hypotension refractory to fluids and inotropic agents, profound coma, and continuing, persisting muscle fasciculation. Death results from progressive, irreversible hypotension, or possibly raised intracranial pressure resulting from cerebral oedema (Torda et al., 1980). These symptoms suggest involvement of both the somatic and autonomic nervous systems. 


\subsubsection{Funnel-web spider antivenom}

In view of the life-threatening envenomation syndrome that may result from the bite of funnel-web spiders, attempts were made to develop an antivenom. Initial work by Wiener to hyperimmunise horses and rabbits failed to produce neutralising antibodies (Wiener, 1963). This may have been due to a number of factors including: (a) the use of female venom which contains very low quantities of the toxin responsible for neurotoxicity; (b) the active neurotoxin binds strongly to a variety of substrates reducing effective doses; and (c) only low levels of antibodies are obtained, even after prolonged immunization, and require concentration by affinity chromatography. Eventually a purified rabbit IgG antivenom raised to the venom of the male $A$. robustus was developed by Dr Struan Sutherland in 1980, then at the Commonwealth Serum Laboratories in Melbourne. Rabbits were immunised with venom and the IgG fraction of their serum was separated by affinity chromatography (Sutherland, 1980). This antivenom was released for clinical evaluation in December 1980 and was freely available from 1984; it represents the only example of the use of immunochemically pure rabbit IgG to treat human envenomation. The antivenom has also been reported to be effective in reversing envenomation from other species of funnel-web spider including $H$. formidabilis, H. infensa, H. species 14, H. cerberea and H. versuta (Hartman and Sutherland, 1984; Dieckmann et al., 1989; Harrington et al., 1999; Miller et al., 2000). More recently, the authors have shown that funnel-web spider antivenom can neutralise the toxicity of a number of other Hadronyche and Atrax spp. venoms from both male and female spiders in vitro (Graudins et al., 2002c).

Since 1980 there have been over 40 cases of funnel-web spider envenomation treated successfully with funnel-web spider antivenom (White et al., 1995). Antivenom therapy has markedly shortened the course of envenomation and resulted in reduced hospital stays as well as reduced the morbidity and mortality from funnel-web spider envenomation (Sutherland and Tibballs, 2001a). Antivenom-treated patients are commonly discharged from hospital within 1 to 3 days of antivenom 
treatment. Prior to antivenom availability the average length of hospital stays for severe, non-fatal cases of envenomation was 14 days (Torda et al., 1980). Nevertheless, funnel-web antivenom is not used frequently and only a handful of cases per year require immunotherapy. The Australian public also has Struan Sutherland to thank for another major advancement in the first aid treatment of funnel-web spider envenomation - the pressure-immobilisation method. This technique, originally developed by Sutherland for the treatment of snake bite (Sutherland et al., 1979), is based on using crêpe bandaging and splinting of the affected limb to produce local pressure and immobilisation. This limits neurotoxin or venom movement, known to occur through the lymphatics (Barnes and Trueta, 1941). This first aid method not only delays the onset of systemic envenomation but may also allow some local destruction or inactivation of the venom (Sutherland, 1980).

\subsubsection{Natural inhibitors of funnel-web spider venom}

Kellaway was the first to study the venom of the funnel-web spider (Kellaway, 1934). He noted the apparent lack of toxicity when mice or guinea-pigs were forcibly bitten by A. robustus. The specificity of funnel-web spider venom for toxicity in primates is now well recognised with a wide range of non-primates only developing symptoms if massive doses of venom are administered, or if the venom is injected intracerebrally (Wallace and Sticka, 1955; Wiener, 1957; 1959; 1963; Duncan et al., 1980; Tibballs et al., 1987; Little et al., 1998a; Sutherland and Tibballs, 2001a). Fortunately workers at the Commonwealth Serum laboratories identified in the early 1970s that 2- or 3-day-old mice appear to be susceptible to the venom. This greatly assisted the in vivo testing of the antivenoms rather than having to use primates. The apparent resistance of non-primates to funnel-web venom is thought to be due to the presence of $\operatorname{IgG}$, and possibly cross-linked $\operatorname{IgG}$ and $\operatorname{IgM}$, inactivating factors in their plasma which bind to the toxins responsible for the envenomation syndrome or may simply involve a non-specific reaction due to the highly basic nature of the toxins (Sheumack et al., 1991). 


\subsection{5. $\delta$-Atracotoxins: isolation and $3 D$ structure}

Early investigations of $A$. robustus venom noted that it was particularly stable under acid conditions or after boiling for up to one hour (Wiener, 1961a) but it was later found that the toxin responsible for neurotoxicity bound strongly to a variety of substrates including acrylamide gel, silica and glass, hampering isolation (Gray and Sutherland, 1978). This explained some of the earlier difficulties with loss of toxicity (Kellaway, 1934; Wiener, 1963). Later studies isolated various crude components of $A$. robustus venom including a 15-25 kDa component 'atraxotoxin' (Sutherland, 1973) and a 9.8 kDa component 'atraxin' (Gregson and Spence, 1983) both of which produced syndromes in monkeys that were indistinguishable from that following injection of whole venom (Mylecharane et al., 1984).

The definitive isolation of the active neurotoxin was achieved by Merlin Howden's group, then at Macquarie University, Sydney. Using various purification techniques, such as ion-exchange and reverse-phase HPLC, the lethal neurotoxin named 'robustoxin' was extracted from the venom of male A. robustus. Early attempts at sequence determination gave conflicting and incorrect results (Gregson and Spence, 1983; Sheumack et al., 1984). The advent of more reliable analysis methods resulted in a proposed amino acid sequence of 42 residues $(4.8 \mathrm{kDa})$ containing eight cysteines (Sheumack et al., 1985).

Due to the large number of different toxins now isolated from the venom of Atrax and Hadronyche spiders, peptide toxins were renamed atracotoxins (ACTX) given that all Australian funnel-web spiders, regardless of genus, belong to the subfamily Atracinae. The same nomenclature, based on that proposed previously for naming individual toxins (Fletcher et al., 1997b), will be used throughout this review: (Greek symbol indicating the target/mode of action, if known)-(ACTX)-(genus and species initials)(Arabic numeral indicating order of discovery in case of toxins with identical activity)(lower case alphabetic character indicating homologue). An in-depth review of the structure- 
function of $\delta$-atracotoxins has recently been published (Nicholson et al., 2004) nevertheless, for completeness, a brief discussion of the structure, target and mode of action of these toxins is presented.

Similar peptides to $\delta$-ACTX-Arla (formerly robustoxin) have subsequently been found in the venom of other Australian funnel-web spiders including $\delta$-ACTX-Hvla (formerly versutoxin) and

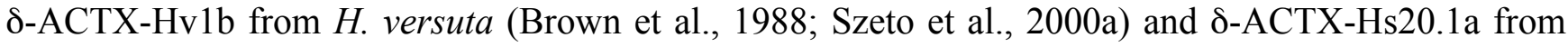
Hadronyche sp. 20 (Nicholson et al., 2004) (Fig. 4A). Both $\delta$-ACTX-Arla and $\delta$-ACTX-Hvla produce an envenomation syndrome in anaesthetised monkeys indistinguishable from that seen in humans suggesting that they are responsible for the physiological effects seen with crude venom (Phillips et al., 1987; Mylecharane et al., 1989; Sheumack et al., 1991). A single primate-specific variant of $\delta$-ACTX-1 is the major active component of most Australian funnel-web spider venoms, but some species produce multiple $\delta$-ACTX-1 homologues (Sheumack et al., 1985; Szeto et al., 2000a). Further screening of $A$. robustus, $H$. valida, $H$. infensa, and $H$. versuta venom gland cDNA libraries has also revealed the presence of 12 novel $\delta$-ACTX-like mature toxins, some with single residue changes while others have greater variation in peptide sequence (D. Wilson and P.F. Alewood, personal communication; B. Sollod and G.F. King, personal communication).

Figure 4 here

All known $\delta$-ACTX are tightly folded 42-residue peptides with no significant sequence homology with any presently known neurotoxins (Sheumack et al., 1985; Brown et al., 1988; Szeto et al., 2000a). The cysteine framework of $\delta$-ACTX is unusual in bioactive peptides due to the occurrence of three contiguous cysteines (Cys ${ }^{14,15,16}$ ) and disulfide-bridged cysteine residues at both the N-and C-termini (Fig. 4A). However a number of spider and marine cone snail toxins have been isolated with a similar cysteine triplet (Ramilo et al., 1992; Corzo et al., 2003; Zeng et al., 2003). The threedimensional solution structures of $\delta$-ACTX-Hvla (Fletcher et al., 1997a) and $\delta$-ACTX-Arla (Pallaghy et al., 1997) have been determined using NMR spectroscopy (Fig. 5A-B). Interestingly, the $\beta$ sheet 
region of the $\delta$-ACTX-1 family of toxins contain a 'disulfide-pseudoknot' (Fig. 5G) which places them in a class of toxins and inhibitory polypeptides with an 'inhibitor cystine-knot' (ICK) motif (Pallaghy et al., 1994; Norton and Pallaghy, 1998). Within this class however, the biological activities of ICK toxins are quite diverse (Norton and Pallaghy, 1998) and this provided few clues to predict the target site of $\delta$-ACTX from their three-dimensional fold and highlight that different biological functions are often grafted onto the same or similar structural scaffolds .

\subsection{6. $\delta$-Atracotoxins: target site and mode of action}

Electrophysiological and neurochemical studies by Graham Nicholson's group at the University of Technology, Sydney have identified the target and mode of action of the $\delta$-ACTXs. These neurotoxins induce spontaneous repetitive firing accompanied by plateau potentials (Grolleau et al., 2001; Alewood et al., 2003). This results in prolonged terminal action potentials in efferent nerve fibres and consequent excessive transmitter release at both autonomic and somatic nerve terminals leading to the symptoms seen during the envenomation syndrome. Using whole-cell patch-clamping, $\delta$-ACTXs were shown by Nicholson and others to produce a slowing of tetrodotoxin (TTX)-sensitive voltagegated sodium channel (VGSC) inactivation. In addition, the toxins caused a modest hyperpolarising shift in the voltage-dependence of activation (Nicholson et al., 1994; Nicholson et al., 1998; Szeto et al., 2000a). The above actions of $\delta$-ACTXs indicate that they inhibit conversion of the VGSC from the open to the inactivated state, resulting in sodium current remaining at membrane potentials where inactivation is normally complete. Interestingly, these actions are very similar, but not identical, to the mechanism of action of scorpion $\alpha$-toxins and sea anemone toxins (Strichartz and Wang, 1986; Hanck and Sheets, 1995) which bind to neurotoxin receptor site 3 on the VGSC (for reviews on VGSC neurotoxin receptor sites see (Cestèle and Catterall, 2000). Subsequent studies by Nicholson's group revealed that $\delta$-ACTXs completely inhibit the binding scorpion $\alpha$-toxins to neurotoxin receptor site- 3 
on rat brain VGSC (Little et al., 1998a; Little et al., 1998b). In collaboration with Dalia Gordon (then at CEA-Saclay, France) they found that binding of $\delta$-ACTXs to VGSC, using ${ }^{125} \mathrm{I}-\delta$-ACTX-Hv1a, revealed a decrease in binding affinity to site 3 under depolarising conditions similar to scorpion $\alpha$--toxins (Gilles et al., 2002). In light of the subtle variations in action and binding properties (Little et al., 1998b; Nicholson et al., 1998), it suggests that $\delta$-ACTX interact at a non-identical yet overlapping site to that of scorpion $\alpha$--toxins at site 3 .

Of interest has been the finding that $\delta$-ACTXs are, in addition to being toxic to mammals, also insecticidal showing similar signs of delayed contractile paralysis as the anti-insect scorpion $\alpha$-toxin LqhaIT (Eitan et al., 1990; Little et al., 1998a). In collaboration with Marcel Pelhate and Bruno Lapied (Université d'Angers, France), Nicholson showed that $\delta$-ACTX-Hv1a modified the action potential of isolated giant axon and dorsal unpaired median neurons of the cockroach Periplaneta americana by prolonging the repolarisation phase, causing the development of spontaneous plateau action potentials. Under voltage-clamp conditions, these alterations in neuronal excitability were found to be due to a slowing of VGSC inactivation and a shift in the voltage-dependence of activation towards more negative potentials (Grolleau et al., 2001). These actions are very similar to LqhaIT (Eitan et al., 1990) and almost identical to that observed in mammalian preparations (Nicholson et al., 1994; Nicholson et al., 1998). Further radioligand binding experiments revealed that $\delta$-ACTXs compete with the insectselective toxin LqhaIT, a well defined ligand of insect VGSC receptor site 3, on cockroach neuronal membranes (Little et al., 1998a; Gilles et al., 2001). Nevertheless, $\delta$-ACTX-Hv1a exhibits a surprisingly low binding affinity to locust VGSC (Gilles et al., 2001). Thus, unlike scorpion toxins, which are only capable of differentiating between mammalian and insects VGSC, $\delta$-ACTXs differentiate between different insect VGSC. Therefore it is clear that the $\delta$-ACTXs are extremely potent and define a new class of toxins affecting both insect and mammalian VGSC. 
Interestingly the three-dimensional fold of these toxins is different from the previously determined structures of the scorpion $\alpha$-toxin Aah-II and the sea anemone toxin anthopleurin-A despite similar actions on VGSC inactivation (Fletcher et al., 1997a). However, the three groups of toxins share a number of topologically related anionic and cationic residues. This allowed the construction of a possible molecular model, based on electrostatic complementarity, to explain how all of these toxins might interact with a patch of charged residues within the S3-S4 loop of domain IV of the VGSC. More recently, structural comparison of $\delta-\mathrm{ACTX}-\mathrm{Hvla}$ to various scorpion toxins suggests a similar putative bioactive surface but a narrower overall shape. This may simplify its association with both cockroach and mammalian receptor site 3 and facilitate its association with different conformations of receptor site-3, correlated with closed/active and slow-inactivated channel states (Gilles et al., 2001).

Recently, Szeto et al. (Szeto et al., 2000a) also isolated and sequenced another novel spider $\delta$-toxin; $\delta$-ACTX-Hvlb (Fig. 4A). This toxin also slows VGSC inactivation but lacks insecticidal activity an action that may be due to the lack of charged residues at positions 4 and 5 of $\delta$-ACTX-Hvlb (Szeto et al., 2000a). This knowledge allows the possibility of manipulating key residues, thus enabling the construction of a $\delta$-ACTX that is insect-selective lacking vertebrate activity. The product would be highly desirable as a bioinsecticide given the potential high selectivity and potency.

\subsection{7. $\omega$ - and $\kappa$-Atracotoxins: insecticidal neurotoxins}

Recent years have seen a noticeable increase in the search for insect-specific spider toxins that may be useful either as insecticide leads, or in defining novel insecticide targets (for reviews see (King et al., 2002; Maggio et al., 2004; Tedford et al., 2004). This is of particular importance following the emergence of insecticide-resistant insect populations (Feyereisen, 1995) and the heightened awareness of environmental and human health risks of classical agrochemicals (Betarbet et al., 2000). 
The original reports of an insecticidal action of funnel-web spider venom dates back to the mid 1950s when Saul Wiener reported that Drosophila were susceptible to A. robustus venom (Drummond and Wiener, 1956; Wiener, 1957). Later work by Ron Atkinson (University of Southern Queensland, Toowoomba) reported the insecticidal potency of $A$. robustus, $H$. versuta and $H$. infensa crude venoms and various venom fractions extracted by reversed-phase HPLC (Atkinson et al., 1996). When injected into the larvae of an economically important agricultural pest the cotton bollworm (Helicoverpa armigera), these partially purified toxins induced essentially identical excitatory syndromes involving continuous writhing followed by death (Atkinson et al., 1996).

Several families of insecticidal neurotoxins have now been isolated, their three-dimensional structures and insectophore (target binding residues) determined. This research has been led by Glenn King's group, formerly at the University of Sydney but now at the University of Connecticut Health Center, USA. These toxins include two structurally distinct families of $\omega$-ACTX, which selectively inhibit insect VGCCs (Fletcher et al., 1997b; Wang et al., 1999; Wang et al., 2001), and the insecticidal к-ACTX (Wang et al., 2000) which recently has been shown to inhibit insect target voltage-gated potassium channels (Gunning et al., 2003b) (for a review of insecticidal ACTXs see King et al., 2002; Maggio et al., 2004; Tedford et al., 2004).

The $\omega$-ACTX-1 group are a family of neurotoxins of 36-37 residues, containing six conserved cysteine residues involved in three disulfide bonds (Figures 4B). $\omega$-ACTX-Hvla selectively acts on the insect voltage-gated calcium channel (VGCC) causing rapid inhibition of whole-cell calcium currents in cockroach neurons (Fletcher et al., 1997b). The three-dimensional structure and insectophore has also been determined for $\omega$-ACTX-Hvla using alanine-scanning mutagenesis (Tedford et al., 2001) (Figures 5C and 5H).

A second family of $\omega$-atracotoxins that specifically block insect VGCCs has also been reported (Wang et al., 2001). The $\omega$-ACTX-2 family contains 41-45 residues with six conserved cysteines that 
form three disulfide bonds and are unrelated to the $\omega$-ACTX-1 family (Figures 4C). The threedimensional structure reveals a highly ordered disulfide-rich N-terminal core domain but a structurally disordered C-terminal domain (Fig. 5D). Interestingly, $\omega$-ACTX-Hv2a shows certain structural, chemical and functional similarities to $\omega$-agatoxin IVA from the unrelated American funnel-web spider Agelenopsis aperta (Kim et al., 1995; Wang et al., 2001). Due to difficulties with expression of $\omega$ ACTX-Hv2a the insectophore is currently unknown.

Finally, another family of three homologous insect-selective neurotoxins has been isolated from the venom of $H$. versuta (Wang et al., 2000). These peptides were originally named the 'Janus-faced' atracotoxins (J-ACTXs) after the two-faced Roman god Janus, due to their asymmetric distribution of charged residues (Wang et al., 2000). Each have 36-37 residues and contain eight conserved cysteine residues with four disulfide bonds (Fig. 4D). The three-dimensional structural investigation reveals an extremely rare vicinal disulfide bridge, which is critical for insecticidal activity (Figures 5E and 5I). However, they show no homology with $\omega$ - or $\delta$-ACTXs (Wang et al., 2000). Unlike the $\omega$-ACTXs the J-ACTXs are excitatory neurotoxins (Fletcher et al., 1997b; Wang et al., 1999). The molecular target of this family of toxins has recently been identified by Nicholson and King as an insect potassium channel (Gunning et al., 2003b) and as such the family has been renamed $\kappa$-ACTX to denote this action. Part of the insectophore (Maggio and King, 2002) also contains the classical Lys-Phe/Tyr diad of other classical $\mathrm{BK}_{\mathrm{Ca}}$ channel blockers (Dauplais et al., 1997) although it would appear that the $\mathrm{Arg}^{8}$ residue in $\kappa$-ACTX family is too bulky to fit in the pore of the potassium channel (Fig. 5I).

Therefore these peptides represent a unique family of insecticidal neurotoxins that would be suitable for future development as novel bioinsecticides. Incorporation of the gene encoding these toxins into insect-selective baculoviruses should increase virus efficacy and reduce time-to-kill such as has been trialled with other toxins (for a recent review see Inceoglu et al., 2001). Although recently this approach has become less favoured due to the growing public concern of the use of genetically 
modified organisms and tight legislation controlling their release, particularly in Europe. Nevertheless mapping of their insectophore using site-directed mutagenesis will provide important information for the rational design of non-peptide mimetics suitable as foliar sprays. This approach has received encouraging validation following successful creation of a non-peptide analogue that topologically mimics the key residues of $\omega$-conotoxin MVIIA, a N-type calcium channel blocker (Menzler et al., 2000). The identification of a range of insect ion channels as previously unvalidated insecticide targets yet again emphasises the necessity for unbiased approaches, not based on the structure or target of existing chemical pesticides, in the discovery of new insecticides. This should hopefully prevent the rapid development of insecticide-resistance already prevalent in many agriculturally and medically important arthropods. Their phyla-specificity also means that there is reduced likelihood of the human or vertebrate toxicity associated with current chemical pesticides.

\subsubsection{Other atracotoxins}

During the search for anti-mammalian and anti-insect toxins a number of other peptides have been isolated from the venom of funnel-web spiders. The first of these was ACTX-Hvf17 a 68 -residue non-toxic peptide with five disulfide bonds isolated from the venom of the Australian funnel-web spider Hadronyche versuta. It does not function like classical neurotoxins in modulating ion channel function as evidenced by its lack of insecticidal activity and its inability to affect skeletal muscle contractility (Szeto et al., 2000b). The polypeptide shows partial sequence homology with a variety of peptides targeting EG-VEGF receptors involved in amongst many activities, gastrointestinal smooth muscle activation (Fig. 4E). These polypeptides include mamba intestinal toxin 1 (MIT1) from the black mamba Dendroaspis p. polylepis (Boisbouvier et al., 1998), Bv8 a small peptide isolated from skin secretions of the toad Bombina variegata (Mollay et al., 1999), the prokineticin family of proteins (also known as endocrine gland-derived, vascular endothelial growth factor or EG-VEGF) (Li et al., 2001), and the C-terminal region of the embryonic head inducer Dickkopf-1 family of proteins (Glinka 
et al., 1998). It also shares some homology with porcine colipase but lacks colipase activity (Szeto et al., 2000b). The sequence homology between these prokineticin-like proteins led King and Nicholson to propose that ACTX-Hvfl7 also adopts the pharmacological feature of prokineticin to stimulate gastrointestinal motility and facilitate the digestive process after the spider has killed its prey. However, we have recently shown that ACTX-Hvf17 does not stimulate smooth muscle contractility on rat stomach fundus or guinea-pig ileum seen with prokineticins and MIT1, nor is the peptide active on other smooth muscle preparations including guinea-pig trachea or rat vas deferens (S. Wen, W.C. Hodgson and G.M. Nicholson, in preparation). Therefore it appears that ACTX-Hvf17 may adopt an ancestral protein fold, refered to as a disulfide-directed $\beta$-hairpin, but that mutation in the primary sequence results in the loss of activity on gastrointestinal smooth muscle.

More recently Paul Alewood's and David Craik's groups at the University of Queensland, Brisbane have determined the primary sequence and three-dimensional structure of ACTX-Hi:OB4219, a novel peptide toxin isolated from the Australian funnel-web spider Hadronyche infensa Orchid Beach (Rosengren et al., 2002). ACTX-Hi:OB4219 contains 38 amino acids with four disulfide bonds (Fig. 4F) forming an ICK motif, a fold consistent with all other ACTX whose structure has been determined to date. Interestingly this toxin possesses two equally populated conformers in solution arising from cis/trans isomerisation of the bond preceding Pro $^{30}$ (Fig. 5F). Despite showing a similar fold to the insect sodium channel toxins $\mu$-Aga-I and $\mu$-Aga-IV (from the unrelated American funnel-web Agelenopsis aperta) and an ICK motif consistent with an ion channel target, ACTX-Hi:OB4219 shows only limited primary sequence homology to the $\mu$-agatoxins and curtatoxins (Fig. 4F) and the target of this toxin is yet to be determined. 


\subsection{Australian mouse spiders: genus Missulena}

\subsubsection{Taxonomy and distribution}

Australian mouse spiders (Araneae: Mygalomorphae: Actinopodidae) belonging to the genus Missulena are primitive hunting spiders. There are eleven species of mouse spider, which are found in all states of Australia except Tasmania. The main species that have been studied so far are the eastern mouse spider, Missulena bradleyi (Fig. 2D) that is distributed along the eastern coastal and highland regions of Australia including the Sydney basin (Fig. 3D) and the northern mouse spider (M. pruinosa) found in Darwin and the Northern Territory (Fig. 3D).

\subsubsection{Clinical manifestations of mouse spider envenomation}

Bites by mouse spiders are very rare, or at least rarely reported, despite their distribution all over the Australian mainland and the habit of males roaming about during daylight hours. However, the general public is not familiar with mouse spiders and often mistakes them for funnel-web spiders or less venomous spiders. The most severe systemic envenomation was in 1985, in Gatton near Toowoomba in Queensland where a 19-month-old girl was bitten on the finger by an identified male M. bradleyi spider. Within 30 minutes the girl began vomiting and lost consciousness. Ensuing symptoms were muscle fasciculation, dyspnoea, hypertension, heavy perspiration and tachycardia. These symptoms resemble those caused by the envenomation of a funnel-web spider and her condition fully recovered after administration of Sydney funnel-web antivenom (Rendle Short, 1985). Additional reports of envenomation have also been documented from various other species of mouse spider. Of the 40 confirmed envenomations where the spider could be identified only the case reported above was associated with severe neurotoxic envenoming (Isbister, 2004). Nevertheless, six bites by M. bradleyi caused local neurotoxic effects such as paraesthesia and diaphoresis and several were associated with minor systemic effects such as headache, nausea and vomiting (Isbister, 2004). This highlights the potentially serious, but rare, nature of systemic mouse spider envenomation. 


\subsubsection{Characterisation of Missulena venoms}

To date there has been very little pharmacological characterisation of the venom of mouse spiders. Crude venom of the red-headed mouse spider M. occatoria appears to be potentially as potent as the Sydney funnel-web spider A. robustus. Missulena occatoria venom was found to have a median lethal dose $\left(\mathrm{LD}_{50}\right)$ of $0.2 \mu \mathrm{g}$ (s.c.) in newborn mice, compared with $2.1 \mu \mathrm{g}$ for male $A$. robustus venom (Sutherland, 1979).

The only other study to be carried out on mouse spider venom was performed by Rash et al. (Rash et al., 2000a). This group showed that male, but not female, M. bradleyi venom produced potent effects on transmitter release on a variety of isolated smooth and skeletal neuromuscular preparations (Rash et al., 2000a). Whole-cell patch clamp experiments using rat dorsal root ganglion neurons revealed that male $M$. bradleyi venom causes a slowing of VGSC inactivation with a modest hyperpolarising shift in the voltage-dependence of activation (Rash et al., 2000a). This action is analogous to that of $\delta$-ACTXs (Nicholson et al., 1994; Nicholson et al., 1998; Szeto et al., 2000a) and it therefore appeared that male M. bradleyi venom may contain a $\delta$-ACTX-like toxin. This was further supported by the clinical finding that Sydney funnel-web antivenom neutralises the toxicity caused by the envenomation of the male M. bradleyi spider both clinically (Rendle Short, 1985) and in vitro (Rash et al., 2000a).

\subsection{4. $\delta$-Missulenatoxins}

Following reverse phase HPLC separation of male M. bradleyi venom, the authors isolated a 42-residue peptide with unusual N- and C-terminal cysteines and a cysteine triplet (Gunning et al., 2003a). This toxin was highly homologous to the $\delta$-ACTX-1 family of toxins from Australian funnel-web spiders including conservation of all eight cysteine residues (Fig. 4A) and was therefore 
named $\delta$-missulenatoxin-Mb1a ( $\delta$-MSTX-Mb1a) in accordance with the nomenclature system for funnel-web spider toxins. Subsequent whole-cell patch-clamp electrophysiology revealed that $\delta$-MSTX-Mb1a modulated VGSC gating and kinetics in a similar fashion to the $\delta$-ACTX-1 family. $\delta$-MSTX-Mb1a therefore provides evidence of a highly conserved spider $\delta$-toxin from a phylogenetically distinct spider family that has not undergone significant modification.

\subsection{Necrotising arachnidism in Australia: fact or fiction?}

In recent years there has been considerable controversy concerning the potential of some spiders to cause necrotic cutaneous lesions. With overseas spiders, such as recluse spiders (Loxosceles spp.), this is well documented (Schenone et al., 1989; Bascur et al., 1992; Futrell, 1992). Conversely in Australia, while many spiders including the white-tailed spider (Lampona spp.), black house spider (Badumna spp.), wolf spiders (Lycosidae) and sac spiders (Cheiracanthium spp.) have been implicated, there is no evidence that spiders cause necrotic arachnidism. The spiders most implicated since the early 1980s are the white-tailed spiders (Lampona cylindrata and L. murina). A recent prospective study by Geoff Isbister of 130 identified white-tailed spider bites showed no cases of necrotic skin lesions (Isbister and Gray, 2003b) and in cases of suspected necrotic ulcers a diagnosis other than spider bite was made following appropriate investigation of bacterial, fungal and mycobacterial cultures and skin biopsy for histopathology (Isbister and Whyte, 2004). This is supported by other clinical (White et al., 1989; Isbister, 2001; Isbister and Gray, 2002) and in vitro studies of the venom (Rash et al., 2000b; Young and Pincus, 2001). For a more complete review of Australian spiders implicated in necrotising arachnidism readers are directed to a recent review (Isbister and White, 2004). 


\section{Australian scorpion toxinology}

\subsection{Taxonomy and distribution}

Scorpions are an ancient group of arthropods, with approximately 1400 species recognised worldwide today, organised into between nine and fourteen families, depending on the classification system followed. There are around 40 named species of Australian scorpions distributed within four families (Fig. 1B), although it is estimated that 150-200 species may exist (E. Volschenk, unpublished data). Unlike their overseas counterparts, scorpions in Australia are rarely encountered and have received little attention (Southcott, 1976). Species from three families are relevant to this review; Lychas marmoreus (family Buthidae), Cercophonius squama (family Bothriuridae) and Urodacus hoplurus (family Urodacidae).

Scorpions of the Buthidae family are highly successful errant opportunists, and are found all across the globe (Lucas and Meier, 1995). They are the dominant scorpions of Africa, America and Asia. They include many of the significantly toxic genera such as Leiurus, Androctonus, Buthus, Centruroides and Tityus. Buthids reached Australia from South East Asia, and have colonised the entire continent except the most southern islands and have given rise to several endemic species and genera (Koch, 1977). Of these Lychas marmoreus is medically relevant and the most widespread (Figures 2E and 3E).

The only medically important member of the Bothriuridae is Cercophonius squama (Figures $2 \mathrm{~F}$ and $3 \mathrm{~F}$ ). This scorpion is widespread across the cooler, moister south and east of the continent (Koch, 1977). While they occupy a similar niche to the buthids, they tend to be more cryptic than buthids, and are thus encountered less often.

The Urodacidae (close relatives of the Scorpionidae) are an endemic family of scorpions found across the continent except on the south-eastern seaboard. The genus Urodacus is the only genus of the family Urodacidae and comprises some 20 described species (Koch, 1977; Volschenk et al., 2000). Due to their burrowing nature they are well suited to drier conditions than the errant scorpions, and are 
consequently the dominant scorpion family over much of the continent. A closely-studied representative example is $U$. hoplurus, (Fig. 2G) which is widespread in western and central Australia (Koch, 1977) (Fig. 3G).

\subsection{Clinical toxicity and laboratory studies}

The medical importance of these Australian scorpions is minor in comparison with the large number of deaths associated with their overseas counterparts in Mexico, the Middle East and North Africa (Dehesa-Davila et al,, 1995). The only Australian scorpions implicated in serious envenomations are the buthid Lychas marmoreus and the bothriurid Cercophonius squama (Sutherland and Tibballs, 2001b; Isbister et al., 2003b). Both of these scorpions are errant in nature, without permanent burrows, and have slender pedipalps and chelicerae. They consequently rely heavily on their venom for predation and for defense. The tiny L. marmoreus appears to have the most dangerous venom to humans (Isbister et al., 2003b). Initial pain and swelling at the sting site is followed by paraesthesia and hyperalgesia lasting for several (1-8) hours, after which numbness and tingling may persist for several days ( $<15 \%$ of cases). Nausea, vomiting, malaise and occasionally tachycardia are seen in $10 \%$ of cases. One well-documented death of an infant girl in West Australia in 1929 was probably due to this scorpion (Southcott, 1976). The second species, C. squama, was probably responsible for the death of a baby girl in Tasmania in the early 1950's, but no documentation exists. Several stings due to this species have occurred also on the mainland too, and the clinical picture includes severe local inflammation and intense pain, accompanied by vomiting and oedema of the whole limb (Sutherland and Tibballs, 2001b). This is borne out by preliminary animal toxicity studies (Wilson and Nicholson, 2003).

The Urodacidae have proportionally much larger pedipalps to catch and crush their prey, and correspondingly less potent anti-mammalian venom (Wilson and Nicholson, 2003). Whilst envenomation from these scorpions is not known to present any risk of fatality, the brief but intense 
localised pain of their stings is well known anecdotally, especially to field biologists (E. Volschenk, personal communication; (Isbister et al., 2003b). More interest has centred on the potential use of insecticidal toxins from urodacid scorpions, as they produce larger amounts of venom than scorpions of the other Australian families, and the potential for novel classes of compound following their extended period of relative isolation (Wilson and Nicholson, 2003). Recently work by two of the authors has identified a novel insect-selective VGSC blocker from the venom of $U$. hoplurus (Wilson et al., 2003).

\section{Australian tick toxinology}

\subsection{Taxonomy and distribution}

Ticks belong to the order Acarina, which also contains mites. Tick toxicosis, a type of paralysis resulting from envenomation following a tick bite, occurs in different regions of the world. Over 60 of the $\sim 820$ tick species (belonging to 10 different genera) having been implicated in paralysis or other signs of toxicosis. However, the extent of tick toxicosis is not known. Worldwide, ticks are of far greater importance as vectors of various diseases, such as Q Fever, tick typhus and Lyme disease, not covered in this review as they do not represent a form of envenomation.

In Australia, tick toxicosis has only been associated with the hard ticks (ticks with a fully sclerotised dorsal plate) of the family Ixodidae (Fig. 1C) that are found along the eastern coastal strip from North Queensland to Victoria (Fig. 3H). This limited distribution is the result of a dependence on environmental conditions such as high humidity and the presence of the natural hosts including various species of bandicoots (Perameles nasuta and Isoodon macrourus) and the koala (Phascolarctos cinereus). In Australia, the main tick species responsible for tick toxicosis is Ixodes holocyclus (Fig. $2 \mathrm{H})$, however there have been several reports that two other tick species, I. cornuatus and I. hirsti are also capable of producing paralysis (Tibballs and Cooper, 1986; Stone and Aylward, 1987). These ticks are very similar in appearance to I. holocyclus but are less common and have a restricted range. 


\subsection{Tick toxicosis}

There have been some 20 fatalities recorded due to bites from ticks in Australia between 1900 and 1945 (Sutherland and Tibballs, 2001c). Importantly this figure is more than the deaths from either red-back or funnel-web spider bites, both of which are considered to be more medically important. In addition, ticks cause countless numbers of deaths in companion and feral animals particularly dogs, which seem especially vulnerable.

Toxicosis caused by I. holocyclus is best characterised in dogs and consists of initial weakness of the hind limbs followed by a rapidly ascending flaccid paralysis. The paresis then increases and extends to the forelimbs and respiratory muscles (Albiston, 1968). Similar symptoms occur in humans, although they may suffer from more serious facial nerve involvement. Other symptoms include loss of appetite and voice, incoordination, excessive vomiting or regurgitation, respiratory distress and often, in the absence of timely antitoxin treatment, death (Stone et al., 1989). This progressive neuromuscular paralysis was thought to result in death due to respiratory failure but it now appears that cardiac dysfunction may contribute (Campbell, 2002).

Initially, tick paralysis was thought to be the result of the transmission of a micro-organism although attempts to identify a pathogen were unsuccessful (Dodd, 1921; Ferguson, 1924). Ian Clunies Ross first demonstrated that the toxic effects on mice and dogs could be produced with an extract of tick salivary glands (Ross, 1926) but it was not until 1983 that the presence of a toxic activity was conclusively demonstrated in tick saliva (Stone et al., 1983a). In this study, female I. holocyclus, partially engorged (4 days) on mice, were attached to an artificial membrane and allowed to feed on a culture medium supplemented with fetal calf serum. The feeding material was collected, concentrated and shown to produce paralysis in mice identical to that observed with salivary gland extracts. 


\subsection{Isolation of salivary neurotoxins}

A toxic fraction of I. holocyclus was first isolated by Kaire at the Commonwealth Serum Laboratories, Melbourne and shown to produce paralysis in dogs consistent with tick toxicosis (Kaire, 1966). This activity could be neutralised by the anti-tick serum that had been commercially produced by the controlled engorgement of female ticks on dogs. The toxic component was shown to be resistant to digestion with proteases (pepsin, trypsin and papain), heating at $75{ }^{\circ} \mathrm{C}$ for $15 \mathrm{~min}$, and moderate $\mathrm{pH}$ (3-9) changes.

Over a 10 year period from the late 70's to late 80's, Dr Bernard Stone and colleagues at the CSIRO Long Pocket Laboratories in Queensland carried out research on I. holocyclus which characterised the feeding processes (Stone et al., 1979), the structure and development of the salivary glands (Stone et al., 1989), immunity to artificial infestation (Stone et al., 1983b) and toxoids (Stone and Neish, 1984; Stone et al., 1986), identified allergens (Gauci et al., 1988), developed improved antitoxin assays (Stone et al., 1982a) and made significant progress in the purification of the paralysing toxin(s) (Stone et al., 1982b; Stone and Aylward, 1987; Stone et al., 1989). Two subsequent studies (Davey et al., 1989; Thurn and Broady, 1992) confirmed the ability to produce a highly toxic fraction from engorged female ticks where the toxic activity was associated with proteins with masses variously reported between $40-80 \mathrm{kDa}$. Similar size toxins were being reported around the same time from other tick species; Rhipicephalus e. evertsi (Viljoen et al., 1986) and Argas (Persicargas) walkerae (Viljoen et al., 1990).

A breakthrough in the identification of the I. holocyclus neurotoxin was made in an experiment where proteins in the partially purified active fraction from engorged salivary glands were radioiodinated, bound to rat brain synaptosomes (pinched-off nerve terminals), separated by SDS-PAGE and visualised by autoradiography (Thurn and Broady, 1992). A single band was seen with $\mathrm{M}_{\mathrm{r}}$ of $5 \mathrm{kDa}$. Subsequent separation by HPLC techniques identified three neurotoxins (holocyclotoxins; HT-1, HT-2 and HT-3). These neurotoxins have masses comparable with those from other arachnids such as spiders 
(3-11 $\mathrm{kDa})$ and scorpions $(5-8 \mathrm{kDa})$. Sufficient HT-1 was purified to obtain a partial amino acid sequence (Thurn, 1994) and this data was used in PCR experiments to isolate the gene encoding the neurotoxin (Masina and Broady, 1999). The gene sequence encodes a mature polypeptide with a calculated mass of $5.9 \mathrm{kDa}$ and a calculated basic $\mathrm{pI}$ of 8.86 . The neurotoxin gene and the leader sequence show strong homology to scorpion neurotoxin genes. Only a single cDNA sequence was obtained. More recently the gene has been isolated from genomic DNA and shown to have the same sequence and no introns (M. Padula and K.W. Broady, unpublished data). These observations suggest that HT-1, HT-2 and HT-3 are derived from a single gene and undergo post-translational modification or partial degradation within the saliva of the tick.

Recombinant forms of HT-1 have been produced in several expression systems (Masina, 1999; Chung, 2001) and shown to be highly immunogenic. However, the antibodies have only demonstrated low levels of protection against tick toxicosis and reactivity to the native toxin. It is interesting to note that cardiotoxic activity recently reported in I. holocyclus (Campbell, 2002) may further complicate the issue of controlling tick toxicosis by vaccination.

\subsection{Mechanism of action of salivary neurotoxins}

Although a purified native or active recombinant neurotoxin from I. holocyclus has not been available for functional characterisation, two studies by Ian Spence (formerly at the Roche Marine Pharmacology Institute, Sydney but now at the University of Sydney) reported electrophysiological experiments on dogs and mice paralysed by I. holocyclus (Cooper and Spence, 1976; Spence, 1979). These studies confirmed the observations of ascending hind limb paralysis and indicated that the neurotoxin(s) acted peripherally at the neuromuscular junction by inhibiting the release of acetylcholine, possibly by inhibiting calcium influx. It was also observed that the effects of the neurotoxin(s) were temperature-dependent with less activity at temperatures below $37^{\circ} \mathrm{C}$. This unusual 
temperature effect was also observed in the synaptosome binding experiments (Thurn and Broady, 1992) where the radiolabelled neurotoxin(s) did not bind at $0{ }^{\circ} \mathrm{C}$.

\subsection{Antivenom}

From the time of the earliest observations (Ross, 1935; Oxer, 1948) that dogs can become immune to tick paralysis and that the passive transfer of serum from immune dogs can arrest tick paralysis in both animals and children (Pearn, 1983), a small veterinary antiserum industry has been operating. This polyclonal hyperimmune antiserum forms the basis of treatment for tick paralysis. It is relatively expensive and only effective if administered early before full flaccid paralysis develops. It is envisaged that the production of active recombinant neurotoxin HT-1 will be a major step towards the development of a protective vaccine against paralysis caused by I. holocyclus.

\section{Conclusions, future directions and further applications}

Despite a recent upsurge of interest in arachnid venoms by various research groups there still remains many challenges for Australian toxinologists. Clinically, there exists the unresolved issues of the effectiveness of intravenous vs. intramuscular antivenom usage, the apparent overdiagnosis of 'necrotic arachnidism', and in many cases the unknown rate and severity of envenomation in several Australian species of spiders and scorpions. Also many arachnid neurotoxins still remain uncharacterised, both biochemically and pharmacologically. This is particularly evident with scorpion and tick neurotoxins. While the development of antivenoms and first aid treatment for spider envenomation is well advanced in Australia, thanks to the labors of clinicians such as the late Struan Sutherland, little is known of antivenom cross-reactivity and efficacy in treating related and unrelated spider envenomation. Is a universal antivenom for theridiid spider envenomation possible? Moreover a tick vaccine still eludes us. 
Given the extensive number of uninvestigated arachnid venoms, there exists a vast treasure of untapped and potentially useful peptides and proteins. Estimates of the peptide diversity of spider venoms indicates that they have a much larger pharmacological inventory than the conopeptides from the venoms of cone snails, currently receiving much attention as sources of potential pharmaceutics. Many of these arachnid toxins are already being investigated as molecular tools in the neurosciences to define the subtype and structure-function of mammalian and/or insect ion channels. In particular, the phyla-specificity of insect-selective atracotoxins has provided a range of previously unvalidated insect targets. Thus spider toxins hold great promise as potential leads in the development of novel biopesticides and target-based insecticide screens.

\section{Acknowledgements}

The authors are grateful to Brianna Sollod, Glenn King, David Wilson and Paul Alewood for communicating results prior to publication and to Philip Lawrence for assistance with arachnid photography. Thanks also to the Rotary Health Research Fund and the Australian Research Council for continued financial support.

\section{References}

Albiston, H.E., 1968. Arthropod infestation - ticks and mites. Australian Government Department of Health, Canberra.

Alewood, D., Birinyi-Strachan, L.C., Pallaghy, P.K., Norton, R.S., Nicholson, G.M., Alewood, P.F., 2003. Synthesis and characterisation of $\delta$-atracotoxin-Arla, the lethal neurotoxin from venom of the Sydney funnel-web spider (Atrax robustus). Biochemistry 42, 12933-12940.

Ashton, A.C., Rahman, M.A., Volynski, K.E., Manser, C., Orlova, E.V., Matsushita, H., Davletov, B.A., van Heel, M., Grishin, E.V., Ushkaryov, Y.A., 2000. Tetramerisation of alpha-latrotoxin 
by divalent cations is responsible for toxin-induced non-vesicular release and contributes to the $\mathrm{Ca}^{2+}$-dependent vesicular exocytosis from synaptosomes. Biochimie 82, 453-468.

Ashton, A.C., Volynski, K.E., Lelianova, V.G., Orlova, E.V., Van Renterghem, C., Canepari, M., Seagar, M., Ushkaryov, Y.A., 2001. $\alpha$-Latrotoxin, acting via two $\mathrm{Ca}^{2+}$-dependent pathways, triggers exocytosis of two pools of synaptic vesicles. J. Biol. Chem. 276, 44695-44703.

Atkinson, R.K., Vonarx, E.J., Howden, M.E.H., 1996. Effects of whole venom and venom fractions from several Australian spiders, including Atrax (Hadronyche) species, when injected into insects. Comp. Biochem. Physiol. 114C, 113-117.

Barker, S.C., Murrell, A., 2002. Phylogeny, evolution and historical zoogeography of ticks: a review of recent progress. Exp. Appl. Acarol. 28, 55-68.

Barnes, J.M., Trueta, J., 1941. Absorption of bacteria toxins and snake venoms from the tissues: importance of the lymphatic circulation. Lancet 1, 623-626.

Bascur, L., Yevenes, I., Barja, P., 1992. Effects of Loxosceles laeta spider venom on blood coagulation. Toxicon 20, 795-796.

Betarbet, R., Sherer, T.B., MacKenzie, G., Garcia-Osuna, M., Panov, A.V., Greenamyre, J.T., 2000. Chronic systemic pesticide exposure reproduces features of Parkinson's disease. Nat. Neurosci. 3, 1301-1306.

Boisbouvier, J., Albrand, J.P., Blackledge, M., Jaquinod, M., Schweitz, H., Lazdunski, M., Marion, D., 1998. A structural homologue of colipase in black mamba venom revealed by NMR floating disulphide bridge analysis. J. Mol. Biol. 283, 205-219.

Brown, M.R., Sheumack, D.D., Tyler, M.I., Howden, M.E.H., 1988. Amino acid sequence of versutoxin, a lethal neurotoxin from the venom of the funnel-web spider Atrax versutus. Biochem. J. 250, 401-405.

Campbell, F.E., 2002. The cardiovascular effects of the toxin/s of the Australian paralysis tick, Ixodes holocyclus. In: Companion Animal Medicine, School of Veterinary Science, University of Queensland, Brisbane.

Cestèle, S., Catterall, W.A., 2000. Molecular mechanisms of neurotoxin action on voltage-gated sodium channels. Biochimie 82, 883-892. 
Chung, J.M.-W., 2001. Expression of a tick toxin for the development of a canine vaccine. MSc Thesis. University of Technology, Sydney.

Clark, R.F., 2001. The safety and efficacy of antivenin Latrodectus mactans. J. Toxicol. - Clin. Toxicol. 39, 125-127.

Clark, R.F., Wethern-Kestner, S., Vance, M.V., Gerkin, R., 1992. Clinical presentation and treatment of black widow spider envenomation: a review of 163 cases. Ann. Emerg. Med. 21, 782-787.

Cleland, J.B., 1932. Injuries and diseases in Australia attributable to animals (other than insects). Med. J. Aust. 1, 157-166.

Cooper, B.J., Spence, I., 1976. Temperature-dependent inhibition of evoked acetylcholine release in tick paralysis. Nature 263, 693-695.

Corzo, G., Gilles, N., Satake, H., Villegas, E., Dai, L., Nakajima, T., Haupt, J., 2003. Distinct primary structures of the major peptide toxins from the venom of the spider Macrothele gigas that bind to sites 3 and 4 in the sodium channel. FEBS Lett 547, 43-50.

Daly, F.F., Hill, R.E., Bogdan, G.M., Dart, R.C., 2001. Neutralization of Latrodectus mactans and L. hesperus venom by redback spider (L. hasselti) antivenom. J. Toxicol. - Clin. Toxicol. 39, 119123.

Dart, R.C., McNally, J., 2001. Efficacy, safety, and use of snake antivenoms in the United States. Ann. Emerg. Med. 37, 181-188.

Dauplais, M., Lecoq, A., Song, J., Cotton, J., Jamin, N., Gilquin, B., Roumestand, C., Vita, C., de Medeiros, C.L., Rowan, E.G., Harvey, A.L., Ménez, A., 1997. On the convergent evolution of animal toxins. Conservation of a diad of functional residues in potassium channel-blocking toxins with unrelated structures. J. Biol. Chem. 272, 4302-4309.

Davey, M.W., Ratcliffe, R., Titchen, D.A., 1989. Aspects of the symptomology and intoxication produced by Ixodes holocyclus. In: Baldo, B. A., Harle, D. G., (Eds.), Proceedings of the Sydney Allergen Groups, Adverse reactions to arthropods in Australia, Vol. 6.

Dehesa-Davila, M., Alagon, A.C., Possani, L.D., 1995. Clinical toxicology of scorpion stings. In: Meier, J., White, J., (Eds.), Handbook of Clinical Toxicology of Animal Venoms and Poisons, CRC Press, New York, pp. 221-238. 
Dieckmann, J., Prebble, J., McDonogh, A., Sara, A., Fisher, M., 1989. Efficacy of funnel-web spider antivenom in human envenomation by Hadronyche species. Med. J. Aust. 151, 706-707.

Dodd, S., 1921. Tick paralysis. J. Comp. Path. Therapy 34, 309.

Drummond, F.H., Wiener, S., 1956. Assay of spider venom and antivenene in Drosophila. Nature 178, 267-268.

Duggin, G., Kilham, H., Kirby, J., 2002. NSW Poisons Information Centre Annual Report 2001.

Duncan, A.W., Tibballs, J., Sutherland, S.K., 1980. Effects of funnel-web spider envenomation in monkeys, and their clinical implications. Med. J. Aust. 2, 429-435.

Eitan, M., Fowler, E., Herrmann, R., Duval, A., Pelhate, M., Zlotkin, E., 1990. A scorpion venom neurotoxin paralytic to insects that affects sodium current inactivation - purification, primary structure, and mode of action. Biochemistry 29, 5941-5947.

Escoubas, P., Diochot, S., Corzo, G., 2000. Structure and pharmacology of spider venom neurotoxins. Biochimie 82, 893-907.

Ferguson, E.W., 1924. Deaths from tick paralysis in human beings. Med. J. Aust. 2, 346-348.

Feyereisen, R., 1995. Molecular biology of insecticide resistance. Toxicol. Lett. 82-83, 83-90.

Fletcher, J.I., Chapman, B.E., Mackay, J.P., Howden, M.E.H., King, G.F., 1997a. The structure of versutoxin ( $\delta$-atracotoxin-Hv1): implications for binding of site-3 toxins to the voltage-gated sodium channel. Structure 5, 1525-1535.

Fletcher, J.I., Smith, R., O'Donoghue, S.I., Nilges, M., Connor, M., Howden, M.E.H., Christie, M.J., King, G.F., 1997b. The structure of a novel insecticidal neurotoxin, $\omega$-atracotoxin-HV1, from the venom of an Australian funnel web spider. Nature Struct. Biol. 4, 559-566.

Futrell, J.M., 1992. Loxoscelism. Am. J. Med. Sci. 304, 261-267.

Gauci, M., Stone, B.F., Thong, Y.H., 1988. Isolation and immunological characterisation of allergens from salivary glands of the Australian paralysis tick Ixodes holocyclus. Int. Arch. Allergy Appl. Immunol. 87, 208-212.

Gilles, N., Harrison, G., Karbat, I., Gurevitz, M., Nicholson, G.M., Gordon, D., 2002. Variations in receptor site-3 on rat brain and insect sodium channels highlighted by binding of a funnel-web spider $\delta$-atracotoxin. Eur. J. Biochem. 269, 1500-1510. 
Gilles, N., Leipold, E., Chen, H., Heinemann, S.H., Gordon, D., 2001. Effect of depolarization on binding kinetics of scorpion $\alpha$-toxin highlights conformational changes of rat brain sodium channels. Biochemistry 40, 14576-14584.

Glinka, A., Wu, W., Delius, H., Monaghan, A.P., Blumenstock, C., Niehrs, C., 1998. Dickkopf-1 is a member of a new family of secreted proteins and functions in head induction. Nature 391, 357362.

Graudins, A., Gunja, N., Broady, K.W., Nicholson, G.M., 2002a. Clinical and in vitro evidence for the efficacy of Australian red-back spider (Latrodectus hasselti) antivenom in the treatment of envenomation by a cupboard spider (Steatoda grossa). Toxicon 40, 767-775.

Graudins, A., Padula, M., Broady, K.W., Nicholson, G.M., 2001. Red-back spider (Latrodectus hasselti) antivenom prevents the toxicity of widow spider venoms. Ann. Emerg. Med. 37, 154160.

Graudins, A., Sung, K.L., Hains, P., Padula, M., Broady, K.W., Nicholson, G.M., 2002b. Partial protein and DNA sequences of Latrodectus hasselti, L. hesperus and L. mactans latrotoxins: are they homologous? Proceedings of the 6th Asia-Pacific Congress on Animal, Plant and Microbial Toxins, Cairns, Australia, pp. 74.

Graudins, A., Wilson, D., Alewood, P.F., Broady, K.W., Nicholson, G.M., 2002c. Cross-reactivity of Sydney funnel-web spider antivenom: Neutralization of the in vitro toxicity of other Australian funnel-web (Atrax and Hadronyche) spider venoms. Toxicon 40, 259-266.

Gray, M.R., 1988. Aspects of the systematics of the Australian funnel web spiders (Araneae: Hexathelidae: Atracinae) based upon morphological and electrophoretic data. In: Austin, A. D., Heather, N. W., (Eds.), Australian Arachnology, The Australian Entomological Society, Brisbane, pp. 113-125.

Gray, M.R., Sutherland, S.K., 1978. Venoms of dipluridae with special reference to Genus Atrax. In: Bettini, S., (Eds.), Handb. Exp. Pharmacol. (Arthropod Venoms), 48, Springer-Verlag, Berlin, pp. 121-148.

Gregson, R.P., Spence, I., 1983. Isolation and characterization of a protein neurotoxin from the venom glands of the funnel-web spider (Atrax robustus). Comp. Biochem. Physiol. 74C, 125-132. 
Grolleau, F., Stankiewicz, M., Birinyi-Strachan, L.C., Wang, X.-H., Nicholson, G.M., Pelhate, M., Lapied, B., 2001. Electrophysiological analysis of the neurotoxic action of a funnel-web spider toxin, $\delta$-atracotoxin-Hvla, on insect voltage-gated $\mathrm{Na}^{+}$channels. J. Exp. Biol. 204, 711-721.

Gunning, S.J., Chong, Y., Khalife, A.A., Hains, P.G., Broady, K.W., Nicholson, G.M., 2003a. Isolation of $\delta$-missulenatoxin-Mbla, the major vertebrate-active spider $\delta$-toxin from the venom of Missulena bradleyi (Actinopodidae). FEBS Letters 554, 211-218.

Gunning, S.J., Maggio, F., King, G.F., Nicholson, G.M., 2003b. Do insecticidal J-atracotoxins target insect potassium channels? Proceedings of the 14th World Congress on Animal, Plant and Microbial Toxins, Adelaide, Australia, pp. 39.

Hanck, D.A., Sheets, M.F., 1995. Modification of inactivation in cardiac sodium channels: ionic current studies with anthopleurin-A toxin. J. Gen. Physiol. 106, 601-616.

Harrington, A.P., Raven, R.J., Bowe, P.C., Hawdon, G.M., Winkel, K.D., 1999. Funnel-web spider (Hadronyche infensa) envenomations in coastal south-east Queensland. Med. J. Aust. 171, 651653.

Hartman, L.J., Sutherland, S.K., 1984. Funnel-web spider (Atrax robustus) antivenom in the treatment of human envenomation. Med. J. Aust. 141, 796-799.

Ho, J., White, J., Staples, A., Hobbs, P., 1999. An analysis of antivenom use in Australia, based on reports of use, 1995-1999. Fifth Asia-Pacific Congress on Animal, Plant and Microbial Toxins, Pattaya, Thailand, pp. 128.

Inceoglu, A.B., Kamita, S.G., Hinton, A.C., Huang, Q., Severson, T.F., Kang, K., Hammock, B.D., 2001. Recombinant baculoviruses for insect control. Pest. Manag. Sci. 57, 981-987.

Ingram, W.W., Musgrave, A., 1933. Spider bite (arachnidism): A survey of its occurrence in Australia, with case histories. Med. J. Aust. 2, 10-15.

Isbister, G., 2001. Necrotic arachnidism in Australia. Toxicon 39, 1941-1943.

Isbister, G.K., 2002. Failure of intramuscular antivenom in red-back spider envenoming. Emerg. Med. (Fremantle) 14, 436-439.

Isbister, G.K., 2004. Mouse spider bites (Missulena spp.) and their medical importance. Med. J. Aust. $180,225-227$. 
Isbister, G.K., Churchill, T.B., Hirst, D.B., Gray, M.R., Currie, B.J., 2001. Clinical effects of bites from formally identified spiders in tropical Northern Territory. Med. J. Aust. 174, 79-82.

Isbister, G.K., Graudins, A., White, J., Warrell, D., 2003a. Antivenom treatment in arachnidism. J. Toxicol. - Clin. Toxicol. 41, 291-300.

Isbister, G.K., Gray, M.R., 2002. A prospective study of 750 definite spider bites, with expert spider identification. Q. J. Med. 95, 723-731.

Isbister, G.K., Gray, M.R., 2003a. Effects of envenoming by comb-footed spiders of the genera Steatoda and Achaearanea (family Theridiidae: Araneae) in Australia. J. Toxicol. - Clin. Toxicol. 41, 809-819.

Isbister, G.K., Gray, M.R., 2003b. White-tail spider bite: a prospective study of 130 definite bites by Lampona species. Med. J. Aust. 179, 199-202.

Isbister, G.K., Gray, M.R., 2003c. Latrodectism: a prospective cohort study of bites by formally identified redback spiders. Med. J. Aust. 179, 88-91.

Isbister, G.K., Gray, M.R., 2004. Bites by Australian mygalomorph spiders (Aranaea, Mygalomorphae), including funel-web spiders (Atracinae) and mouse spiders (Actinopodidae: Missulena spp). Toxicon 43, 133-140.

Isbister, G.K., Volschenk, E.S., Balit, C.R., Harvey, M.S., 2003b. Australian scorpion stings: a prospective study of definite stings. Toxicon $41,877-883$.

Isbister, G.K., White, J., 2004. Clinical consequences of spider bites: recent advances in our understanding. Toxicon in press.

Isbister, G.K., Whyte, I.M., 2004. Suspected white-tail spider bite and necrotic ulcers. Intern. Med. J. $34,38-44$.

Jackson, E.S., 1927. The red-backed spider bite. Med. J. Aust. 1, 525.

Kaire, G.H., 1966. Isolation of tick paralysis toxin from Ixodes holocyclus. Toxicon 4, 91-97.

Kellaway, C.H., 1934. A note on the venom of the Sydney funnel-web spider Atrax robustus. Med. J. Aust. 1, 678-679. 
Kim, J.I., Konishi, S., Iwai, H., Kohno, T., Gouda, H., Shimada, I., Sato, K., Arata, Y., 1995. Threedimensional solution structure of the calcium channel antagonist $\omega$-agatoxin IVA: consensus molecular folding of calcium channel blockers. J. Mol. Biol. 250, 659-671.

King, G.F., Tedford, H.W., Maggio, F., 2002. Structure and function of insecticidal neurotoxins from Australian funnel-web spiders. J. Toxicol. - Toxin Rev. 21, 359-389.

Kirby, J., 1998. 1998 Annual Report of the New South Wales Poisons Information Centre. The New Children's Hospital, Sydney.

Koch, L.E., 1977. The taxonomy, geographic distribution and evolutionary radiation of AustraloPapuan scorpions. Rec. West. Aust. Mus. 5, 83-367.

Korszniak, N.V., Story, D.F., 1994. Effects of the venom of the Theridiid spider Steatoda capensis Hann, on autonomic transmission in rat isolated atria and caudal artery. Toxicon 32, 85-96.

Li, M., Bullock, C.M., Knauer, D.J., Ehlert, F.J., Zhou, Q.Y., 2001. Identification of two prokineticin cDNAs: recombinant proteins potently contract gastrointestinal smooth muscle. Mol. Pharmacol. 59, 692-698.

Little, M.J., Wilson, H., Zappia, C., Cestèle, S., Tyler, M.I., Martin-Eauclaire, M.-F., Gordon, D., Nicholson, G.M., 1998a. ס-Atracotoxins from Australian funnel-web spiders compete with scorpion $\alpha$-toxin binding on both rat brain and insect sodium channels. FEBS Lett. 439, 246252.

Little, M.J., Zappia, C., Gilles, N., Connor, M., Tyler, M.I., Martin-Eauclaire, M.-F., Gordon, D., Nicholson, G.M., 1998b. $\delta$-Atracotoxins from Australian funnel-web spiders compete with scorpion $\alpha$-toxin binding but differentially modulate alkaloid toxin activation of voltage-gated sodium channels. J. Biol. Chem. 273, 27076-27083.

Lucas, S.M., Meier, J., 1995. Biology and distribution of scorpions of medical importance. In: Meier, J., White, J., (Eds.), Handbook of Clinical Toxicology of Animal Venoms and Poisons, CRC Press, New York, pp. 205-219.

Maggio, F., King, G.F., 2002. Scanning mutagenesis of a Janus-faced atracotoxin reveals a bipartite surface patch that is essential for neurotoxic function. J. Biol. Chem. 277, 22806-22813. 
Maggio, F., Sollod, B.L., Tedford, H.W., King, G.F., 2004. Spider toxins and their potential for insect control. In: Gilbert, L. I., Iatrou, K., Gill, S., (Eds.), Comprehensive Molecular Insect Science, Elsevier, in press.

Maretic, Z., 1983. Latrodectism: variations in clinical manifestations provoked by Latrodectus species of spiders. Toxicon 21, 457-466.

Masina, S., 1999. The sequence, expression and immunological characterisation of the HT-1 neurotoxin from the Australian paralysis tick Ixodes holocyclus. PhD Thesis. University of Technology, Sydney.

Masina, S., Broady, K.W., 1999. Tick paralysis: development of a vaccine. Int. J. Parasitol. 29, 535541.

Menzler, S., Bikker, J.A., Suman-Chauhan, N., Horwell, D.C., 2000. Design and biological evaluation of non-peptide analogues of $\omega$-conotoxin MVIIA. Bioorg Med Chem Lett 10, 345-347.

Miller, M.K., Whyte, I.M., White, J., Keir, P.M., 2000. Clinical features and management of Hadronyche envenomation in man. Toxicon 38, 409-427.

Mollay, C., Wechselberger, C., Mignogna, G., Negri, L., Melchiorri, P., Barra, D., Kreil, G., 1999. Bv8, a small protein from frog skin and its homologue from snake venom induce hyperalgesia in rats. Eur. J. Pharmacol. 374, 189-196.

Muller, G.J., 1993. Black and brown widow spider bites in South Africa. A series of 45 cases. South African Med. J. 83, 399-405.

Mylecharane, E.J., Spence, I., Gregson, R.P., 1984. In vivo actions of atraxin, a protein neurotoxin from the venom glands of the funnel-web spider (Atrax robustus). Comp. Biochem. Physiol. 79C, 395-399.

Mylecharane, E.J., Spence, I., Sheumack, D.D., Claassens, R., Howden, M.E.H., 1989. Actions of robustoxin, a neurotoxic polypeptide from the venom of the male funnel-web spider (Atrax robustus), in anaesthetized monkeys. Toxicon 27, 481-492.

Nicholson, G.M., Graudins, A., 2002. Spiders of medical importance in the Asia-Pacific: atracotoxin, latrotoxin and related spider neurotoxins. Clin. Exp. Pharmacol. Physiol. 29, 785-794. 
Nicholson, G.M., Graudins, A., 2003. Antivenoms for the treatment of spider envenomation. J. Toxicol.-Toxin Rev. 23, 81-106.

Nicholson, G.M., Little, M., Birinyi-Strachan, L.C., 2004. Structure and function of $\delta$-atracotoxins: lethal neurotoxins targeting the voltage-gated sodium channel. Toxicon 43, 587-599.

Nicholson, G.M., Walsh, R., Little, M.J., Tyler, M.I., 1998. Characterisation of the effects of robustoxin, the lethal neurotoxin from the Sydney funnel-web spider Atrax robustus, on sodium channel activation and inactivation. Pflügers Archiv. (Eur. J. Physiol.) 436, 117-126.

Nicholson, G.M., Willow, M., Howden, M.E.H., Narahashi, T., 1994. Modification of sodium channel gating and kinetics by versutoxin from the Australian funnel-web spider Hadronyche versuta. Pflügers Archiv. (Eur. J. Physiol.) 428, 400-409.

Norton, R.S., Pallaghy, P.K., 1998. The cystine knot structure of ion channel toxins and related polypeptides. Toxicon $36,1573-1583$.

Orlova, E.V., Rahman, M.A., Gowen, B., Volynski, K.E., Ashton, A.C., Manser, C., van Heel, M., Ushkaryov, Y.A., 2000. Structure of $\alpha$-latrotoxin oligomers reveals that divalent cationdependent tetramers form membrane pores. Nat. Struct. Biol. 7, 48-53.

Oxer, D.T., 1948. The preparation of canine anti-tick serum. Aust. Vet. J. 24, 95.

Pallaghy, P.K., Alewood, D., Alewood, P.F., Norton, R.S., 1997. Solution structure of robustoxin, the lethal neurotoxin from the funnelweb spider Atrax robustus. FEBS Lett. 419, 191-196.

Pallaghy, P.K., Neilsen, K.J., Craik, D.J., Norton, R.S., 1994. A common structural motif incorporating a cystine knot and a triple-stranded $\beta$-sheet in toxic and inhibitory polypeptides. Protein Sci. 3, 1833-1839.

Pearn, J.H., 1983. Clinical aspects of tick envenomation of humans. Toxicon Suppl., 3, 349.

Phillips, C.A., Spence, I., Mylecharane, E.J., Brown, M.R., Sheumack, D.D., Claassens, R., Howden, M.E.H., 1987. The effects of the venom from the Blue Mountains funnel-web spider (Atrax versutus) in anaesthetized monkeys. Clin. Exp. Pharmacol. Physiol. Suppl 10, 14-15.

Platnick, N.I., 1997. Advances in Spider Taxonomy, 1992-1995: with Redescriptions 1940-1980. New York Entomological Society \& The American Museum of Natural History. 
Prendini, L., 2000. Phylogeny and classification of the superfamily Scorpionoidea Latreille 1802 (Chelicerata, Scorpiones): an exemplar approach. Cladistics 16, 1-78.

Ramilo, C.A., Zafaralla, G.C., Nadasdi, L., Hammerland, L.G., Yoshikami, D., Gray, W.R., Kristipati, R., Ramachandran, J., Miljanich, G., Olivera, B.M., Cruz, L.J., 1992. Novel $\alpha$ - and $\omega-$ conotoxins from Conus striatus venom. Biochemistry 31, 9919-9926.

Rash, L.D., Birinyi-Strachan, L.C., Nicholson, G.M., Hodgson, W.C., 2000a. Neurotoxic activity of venom from the Australian eastern mouse spider (Missulena bradleyi) involves modulation of sodium channel gating. Brit. J. Pharmacol. 130, 1817-1824.

Rash, L.D., Hodgson, W.C., 2002. Pharmacology and biochemistry of spider venoms. Toxicon 40, $225-254$.

Rash, L.D., King, R.G., Hodgson, W.C., 2000b. Sex differences in the pharmacological activity of venom from the white-tailed spider (Lampona cylindrata). Toxicon 38, 1111-1127.

Raven, R.J., 1988. The current status of Australian spider systematics. In: Austin, A. D., Heather, N. W., (Eds.), Australian Arachnology, Miscellaneous Publication No. 5, Australian Entomological Society.

Rendle Short, H., 1985. Mouse spider envenomation. Proceedings of the Australian and New Zealand Intensive Care Society Scientific Meeting, Brisbane, pp. 25.

Rosengren, K.J., Wilson, D., Daly, N.L., Alewood, P.F., Craik, D.J., 2002. Solution structures of the cis- and trans-Pro30 isomers of a novel 38-residue toxin from the venom of Hadronyche infensa sp. that contains a cystine-knot motif within its four disulfide bonds. Biochemistry 41, 32943301.

Ross, I.C., 1926. An experimental study of tick paralysis in Australia. Parasitology 18, 410.

Ross, I.C., 1935. Tick paralysis: a fatal disease of dogs and other animals in eastern Australia. J. Council Scientific Industrial Res., Australia 8, 8.

Schenone, H., Savedra, T., Rojas, A., Vilaroel, F., 1989. Loxoscelismo en Chile: estudios epidemiologicos clinicos y experimentales. Rev. Inst. Med. Trop. Sao Paulo 36, 403-415. 
Sheumack, D.D., Baldo, B.A., Carroll, P.R., Hampson, F., Howden, M.E., Skorulis, A., 1984. A comparative study of properties and toxic constituents of funnel web spider (Atrax) venoms. Comp. Biochem. Physiol. 78C, 55-68.

Sheumack, D.D., Claassens, R., Whiteley, N.M., Howden, M.E.H., 1985. Complete amino acid sequence of a new type of lethal neurotoxin from the venom of the funnel-web spider Atrax robustus. FEBS Lett. 181, 154-156.

Sheumack, D.D., Comis, A., Claassens, R., Mylecharane, E.J., Spence, I., Howden, M.E.H., 1991. An endogenous antitoxin to the lethal venom of the funnel web spider, Atrax robustus, in rabbit sera. Comp. Biochem. Physiol. 99C, 157-161.

South, M., Wirth, P., Winkel, K.D., 1998. Redback spider antivenom used to treat envenomation by a juvenile Steatoda spider. Med. J. Aust. 169, 642.

Southcott, R.V., 1976. Arachnidism and allied syndromes in the Australian region. Rec. Adel. Child. Hosp. 1, 97-186.

Spence, I., 1979. Electrophysiological studies of the venom of the funnel-web spider Atrax robustus and the tick Ixodes holocyclus. In: Chubb, I. W., Geffen, L.B., (Eds.), Neurotoxins: Fundamental and Clinical Advances, Adelaide University Union Press, Adelaide, pp. 161.

Stone, B.F., Aylward, J.H., 1987. Tick toxicosis and the causal toxins: tick paralysis. In: Gopalakhrishnakone, P., Tan, C. K., (Eds.), Progress in Venom and Toxin Research, National University of Singapore Press, Singapore, pp. 594-602.

Stone, B.F., Binnington, K.C., Gauci, M., Aylward, J.H., 1989. Tick/host interactions for Ixodes holocyclus: role, effects, biosynthesis and nature of its toxic and allergenic oral secretions. Exp. Appl. Acarol. 7, 59-69.

Stone, B.F., Commins, M.A., Kemp, D.H., 1983a. Artificial feeding of the Australian paralysis tick, Ixodes holocyclus and collection of paralysing toxin. Int. J. Parasitol. 13, 447-454.

Stone, B.F., Cowie, M.R., Kerr, J.D., Binnington, K.C., 1982a. Improved toxin/antitoxin assays for studies on the Australian paralysis tick Ixodes holocyclus. Aust. J. Exp. Biol. Med. Sci. 60, 309318. 
Stone, B.F., Double, B.M., Binnington, K.C., Goodger, B.V., 1979. Toxins of the Australian paralysis tick Ixodes holocyclus. In: Rodriguez, J. G., (Eds.), Recent Advances in Acarology, Vol. 1, Academic Press, New York, pp. 347-356.

Stone, B.F., Neish, A.L., 1984. Tick-paralysis toxoid: an effective immunizing agent against the toxin of Ixodes holocyclus. Aust. J. Exp. Biol. Med. Sci. 62, 189-191.

Stone, B.F., Neish, A.L., Morrison, J.J., Uren, M.F., 1986. Toxoid stimulation in dogs of high titres of neutralising antibodies against holocyclotoxin, the paralysing toxin of the Australian paralysis tick Ixodes holocyclus. Aust. Vet. J. 63, 125-127.

Stone, B.F., Neish, A.L., Wright, I.G., 1982b. Immunization of rabbits to produce high serum titres of neutralizing antibodies and immunity to the paralyzing toxin of Ixodes holocyclus. Aust. Exp. Biol. Med. Sci. 60, 351-358.

Stone, B.F., Neish, A.L., Wright, I.G., 1983b. Tick (Ixodes holocyclus) paralysis in the dog-quantitative studies on immunity following artificial infestation with the tick. Aust. Vet. J. 60, 65-68.

Strichartz, G.R., Wang, G.K., 1986. Rapid voltage-dependent dissociation of scorpion $\alpha$-toxins coupled to Na channel inactivation in amphibian myelinated nerves. J. Gen. Physiol. 88, 413-435.

Sudhof, T.C., 2001. $\alpha$-Latrotoxin and its receptors: neurexins and CIRL/latrophilins. Annu. Rev. Neurosci. 24, 933-962.

Sutherland, S.K., 1973. Isolation, mode of action and properties of the major toxin (Atraxotoxin) in the venom of the Sydney funnel-web spider (Atrax robustus). Proc. Aust. Soc. Med. Res. 3, 172.

Sutherland, S.K., 1979. Clinical and experimental aspects of arachnid poisoning in Australia. In:

Chubb, I. W., Geffen, L. B., (Eds.), Neurotoxins, Fundamental and Clinical Advances, Adelaide University Union Press, Adelaide, pp. 151-160.

Sutherland, S.K., 1980. Antivenom to the venom of the male Sydney funnel-web spider Atrax robustus. Preliminary report. Med. J. Aust. 2, 437-441.

Sutherland, S.K., Coulter, A.R., Harris, R.D., 1979. Rationalisation of first-aid measures for elapid snakebite. Lancet 1, 183-186. 
Sutherland, S.K., Tibballs, J., 2001a. The genera Atrax and Hadronyche, Funnel-web spiders. In: Australian Animal Toxins: The Creatures, Their Toxins and Care of the Poisoned Patient, Oxford University Press, Melbourne, pp. 402-464.

Sutherland, S.K., Tibballs, J., 2001b. Venomous arthropods of medical importance, other than spiders and ticks. In: Australian Animal Toxins: The Creatures, Their Toxins and Care of the Poisoned Patient, Oxford University Press, Melbourne, pp. 489-533.

Sutherland, S.K., Tibballs, J., 2001c. Ticks. In: Australian Animal Toxins: The Creatures, Their Toxins and Care of the Poisoned Patient, 2, Oxford University Press, Melbourne, pp. 465-488.

Sutherland, S.K., Tibballs, J., 2001d. Latrodectus hasselti, the red-back or jockey spider. In: Australian Animal Toxins: The Creatures, Their Toxins and Care of the Poisoned Patient, 2, Oxford University Press, Melbourne, pp. 383-401.

Sutherland, S.K., Trinca, J.C., 1978. Survey of 2144 cases of red-back spider bites: Australia and New Zealand, 1963-1976. Med. J. Aust. 2, 620-623.

Szeto, T.H., Birinyi-Strachan, L.C., Wang, X.-H., Smith, R., Connor, M., Christie, M.J., King, G.F., Nicholson, G.M., 2000a. Isolation and pharmacological characterisation of $\delta$-atracotoxin-Hv1b, a vertebrate-selective sodium channel toxin. FEBS Lett. 470, 293-299.

Szeto, T.H., Wang, X.-H., Smith, R., Connor, M., Christie, M.J., Nicholson, G.M., King, G.F., $2000 b$. Isolation of a funnel web spider polypeptide with homology to mamba intestinal toxin 1 and the embryonic head inducer Dickkopf1. Toxicon 38, 429-442.

Tedford, H.W., Fletcher, J.I., King, G.F., 2001. Functional significance of the $\beta$-hairpin in the insecticidal neurotoxin $\omega$-atracotoxin-Hvla. J. Biol. Chem. 276, 26568-26576.

Tedford, H.W., Maggio, F., Sollod, B.L., King, G.F., 2004. Australian funnel-web spiders: master insectide chemists. Toxicon 43, 601-618.

Thurn, M.J., 1994. Tick toxinology: isolation and characterisation of the toxin from the Australian paralysis tick, Ixodes holocyclus. PhD Thesis. University of Technology, Sydney.

Thurn, M.J., Broady, K.W., 1992. A tick toxin. In: Watters, D., Lavin, M., Maguire, D., Pearn, J., (Eds.), Toxins and Targets, Harwood Academic, New York, pp. 75-80. 
Tibballs, J., Cooper, S.J., 1986. Paralysis with Ixodes cornuatus envenomation. Med. J. Aust. 145, 3738.

Tibballs, J., Sutherland, S.K., Duncan, A.W., 1987. Effects of male Sydney funnel-web spider venom in a dog and a cat. Aust. Vet. J. 64, 63-64.

Torda, T.A., Loong, E., Greaves, I., 1980. Severe lung oedema and fatal consumption coagulopathy after funnel-web bite. Med. J. Aust. 2, 442-444.

Trethewy, C.E., Bolisetty, S., Wheaton, G., 2003. Red-back spider envenomation in children in Central Australia. Emerg. Med. (Fremantle) 15, 170-175.

Ushkaryov, Y., 2002. Alpha-latrotoxin: from structure to some functions. Toxicon 40, 1-5.

Ushkaryov, Y.A., Volynski, K.E., Ashton, A.C., 2004. The multiple actions of black widow spider toxins and their selective use in neurosecretion studies. Toxicon 43, 527-542.

Viljoen, G.J., Bezuidenhout, J.D., Oberem, P.T., Vermeulen, N.M., Visser, L., Gothe, R., Neitz, A.W., 1986. Isolation of a neurotoxin from the salivary glands of female Rhipicephalus evertsi evertsi. J. Parasitol. 72, 865-874.

Viljoen, G.J., Van Wyngaardt, S., Gothe, R., Visser, L., Bezuidenhout, J.D., Neitz, A.W., 1990. The detection and isolation of a paralysis toxin present in Argas (Persicargas) walkerae. Onderstepoort J. Vet. Res. 57, 163-168.

Volschenk, E.S., Smith, G.T., Harvey, M.S., 2000. A new species of Urodacus from Western Australia, with additional descriptive notes for Urodacus megamastigus. Rec. West. Aust. Mus. 20, 57-67.

Wallace, A.L., Sticka, R., 1955. The effect of ACTH on the toxicity of spiders' venom. Med. J. Aust. 1, $5-6$.

Wang, X.-H., Connor, M., Smith, R., Maciejewski, M.W., Howden, M.E.H., Nicholson, G.M., Christie, M.J., King, G.F., 2000. Discovery and characterization of a family of insecticidal neurotoxins with a rare vicinal disulfide bridge. Nature Struct. Biol. 7, 505-513.

Wang, X.-H., Connor, M., Wilson, D., Wilson, H., Nicholson, G.M., Smith, R., Shaw, D., Mackay, J.P., Alewood, P.F., Christie, M.J., King, G.F., 2001. Biopesticide panning: discovery of a potent and highly specific peptide antagonist of insect calcium channels. J. Biol. Chem. 276, 40306-40312. 
Wang, X.-H., Smith, R., Fletcher, J.I., Wilson, H., Wood, C.J., Howden, M.E.H., King, G.F., 1999. Structure-function studies of $\omega$-atracotoxin, a potent antagonist of insect voltage-gated calcium channels. Eur. J. Biochem. 264, 488-494.

White, J., 1998. Envenoming and antivenom use in Australia. Toxicon 36, 1483-1492.

White, J., Carduso, J.L., Fan, H.W., 1995. Clinical toxicology of spider bites. In: Meier, J., White, J., (Eds.), Handbook of Clinical Toxicology of Animal Venoms and Poisons, CRC Press, New York, pp. 259-329.

White, J., Hirst, D., Hender, E., 1989. 36 cases of bites by spiders, including the white-tailed spider, Lampona cylindrata. Med. J. Aust. 150, 401-403.

Wiener, S., 1956a. The Australian red back spider (Latrodectus hasseltii). II. Effect of temperature on the toxicity of venom. Med. J. Aust. 43, 331-334.

Wiener, S., 1956b. The Australian red back spider (Latrodectus hasseltii): I. Preparation of antiserum by the use of venom adsorbed on aluminum phosphate. Med. J. Aust. 43, 739-742.

Wiener, S., 1957. The Sydney funnel-web spider (Atrax robustus) I. Collection of venom and its toxicity in animals. Med. J. Aust. 2, 377-382.

Wiener, S., 1959. The Sydney funnel-web spider (Atrax robustus) II. Venom yield and other characteristics of spider in captivity. Med. J. Aust. 2, 679-682.

Wiener, S., 1961a. Observations on the venom of the Sydney funnel-web spider (Atrax robustus). Med. J. Aust. 2, 693-699.

Wiener, S., 1961b. Red back spider antivenene. Med. J. Aust. 2, 41-44.

Wiener, S., 1963. Antigenic and electrophoretic properties of funnel-web spider (Atrax robustus) venom. In: Keegan, H. L., MacFarlane, W. V., (Eds.), Venomous and Poisonous Animals and Noxious Plants of the Pacific Region, Pergamon Press, London.

Wilson, H.I., Hains, P.G., Nicholson, G.M., 2003. The venom of Australian Urodacus scorpions (Arachnidae: Scorpiones: Urodacidae) contains a novel class of insect-selective sodium channel-blocking toxins. Proceedings of the 14th World Congress on Animal, Plant and Microbial Toxins, Adelaide, Australia, pp. 57. 
Wilson, H.I., Nicholson, G.M., 2003. Characteristics of the venom of Australian urodacid and buthid scorpions: venom production, composition and toxicity. Proceedings of the 14th World Congress on Animal, Plant and Microbial Toxins, Adelaide, Australia, pp. 66.

Winkel, K.D., Harvey, M.S., Wirth, P., 2000. Steatodism treated with redback spider antivenom. Joint ACITHN \& ACTM 2000 Conference, Brisbane, pp.

Woo, K.M., Smart, D.R., 1999. The clinical effects of spider bites in southern Tasmania. Emerg. Med. (Fremantle) 11, 145-149.

Young, A.R., Pincus, S.J., 2001. Comparison of enzymatic activity from three species of necrotising arachnids in Australia: Loxosceles rufescens, Badumna insignis and Lampona cylindrata. Toxicon 39, 391-400.

Zeng, X.Z., Xiao, Q.B., Liang, S.P., 2003. Purification and characterization of raventoxin-I and raventoxin-III, two neurotoxic peptides from the venom of the spider Macrothele raveni. Toxicon 41, 651-656.

Zukowski, C.W., 1993. Black widow spider bite. J. Am. Board Fam. Pract. 6, 279-281. 


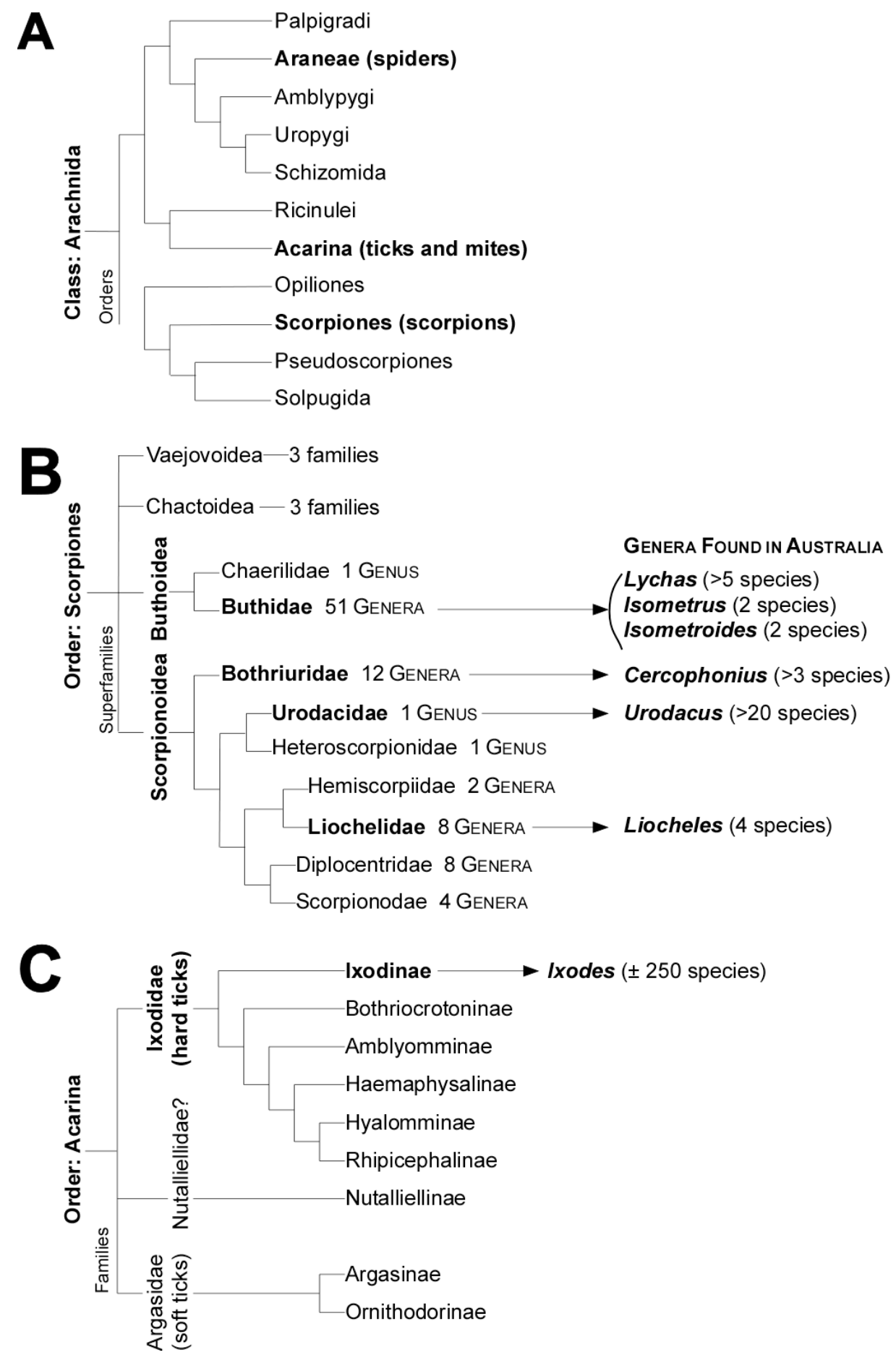

Fig. 1. Partial taxonomy of medically important Australian arachnids. (A) Relationship of the orders Aranaea, Acarina and Scorpiones within the Class Arachnida. (B) Taxonomy of the order Scorpiones, with particular reference to the families represented in Australia (modified from (Prendini, 2000). (C) Taxonomy of the order Acarina (modified from (Barker and Murrell, 2002). 

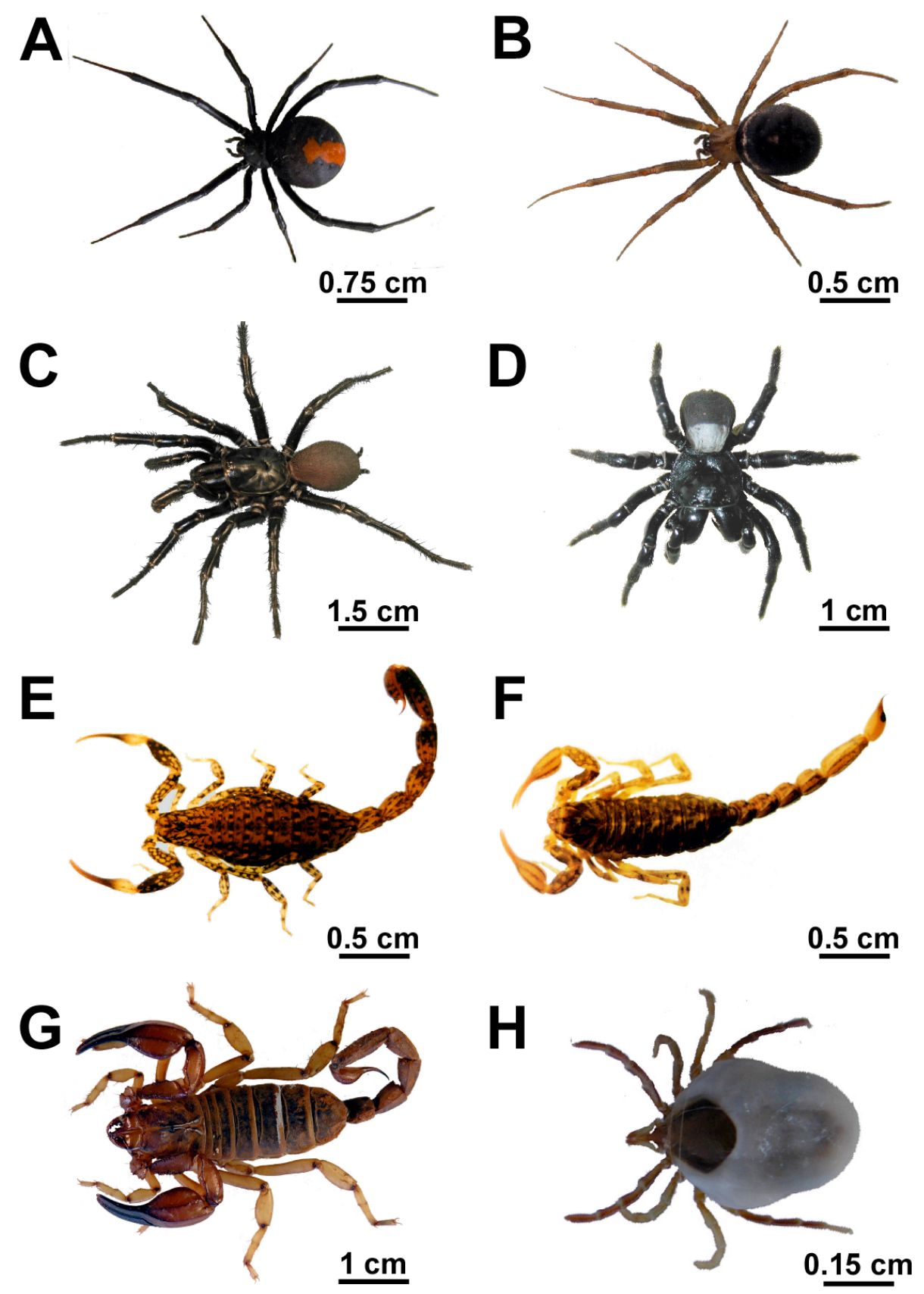

Fig. 2. Medically important Australian arachnids. (A) Female red-back spider (Latrodectus hasselti).

(B) Female cupboard spider (Steatoda grossa). (C) Male Sydney funnel-web spider (Atrax robustus). (D) Male eastern mouse spider (Missulena bradleyi). (E) Female little marbled scorpion (Lychas marmoreus). (F) Female Cercophonius squama. (G) Female Urodacus hoplurus. (H) Partially engorged female Australian paralysis tick (Ixodes holocyclus). 

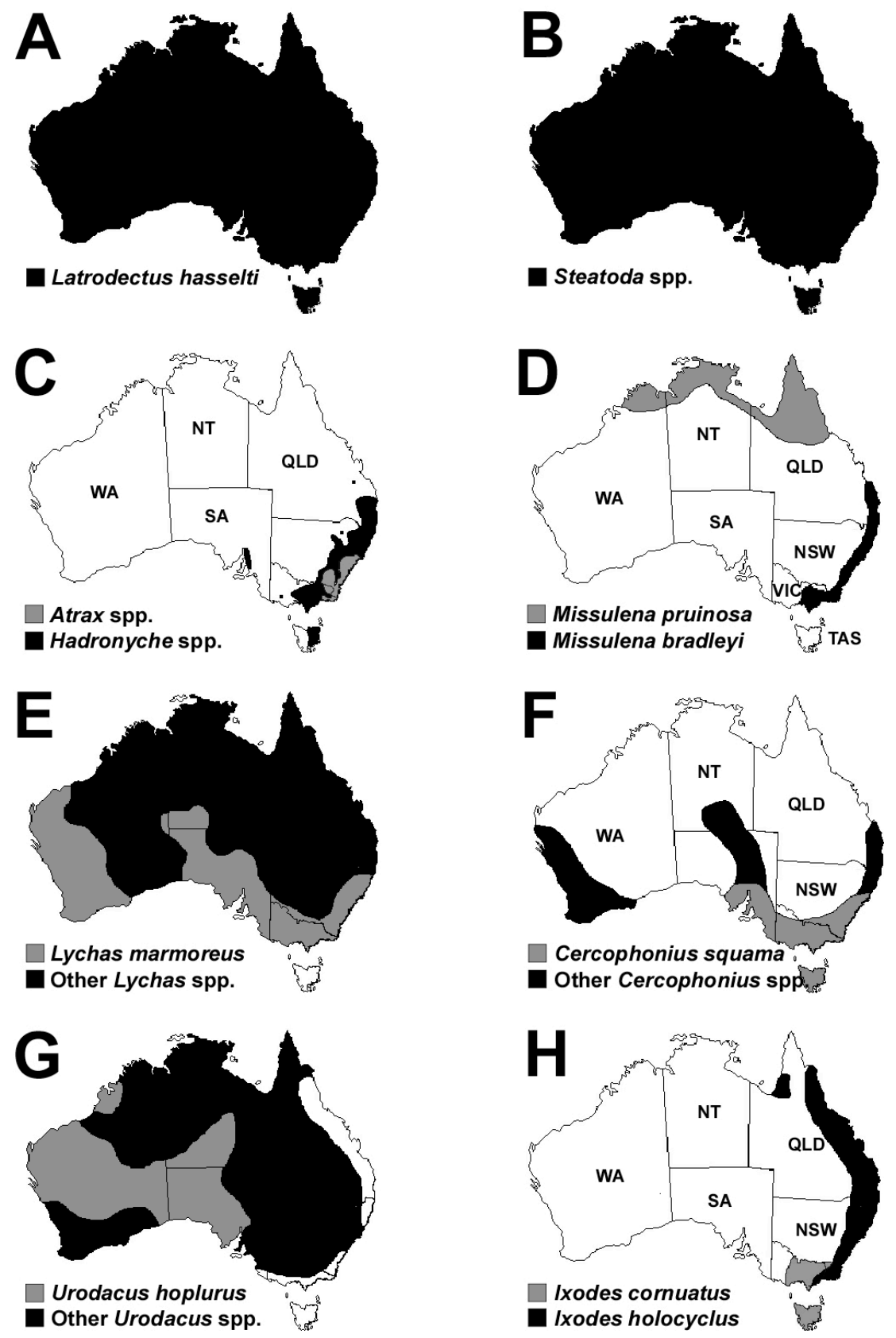

Fig. 3. Distribution maps of medically important Australian arachnids. (A) Red-back spider (Latrodectus hasselti). (B) Cupboard spiders (Steatoda spp.). (C) Funnel-web spiders (Atrax and Hadronyche spp.). (D) Eastern mouse (Missulena bradleyi) and northern mouse spiders (M. pruinosa).

(E) Little marbled scorpion (Lychas marmoreus) (F) Cercophonius squama. (G) Urodacus hoplurus. (H) Australian paralysis ticks (Ixodes spp.). 

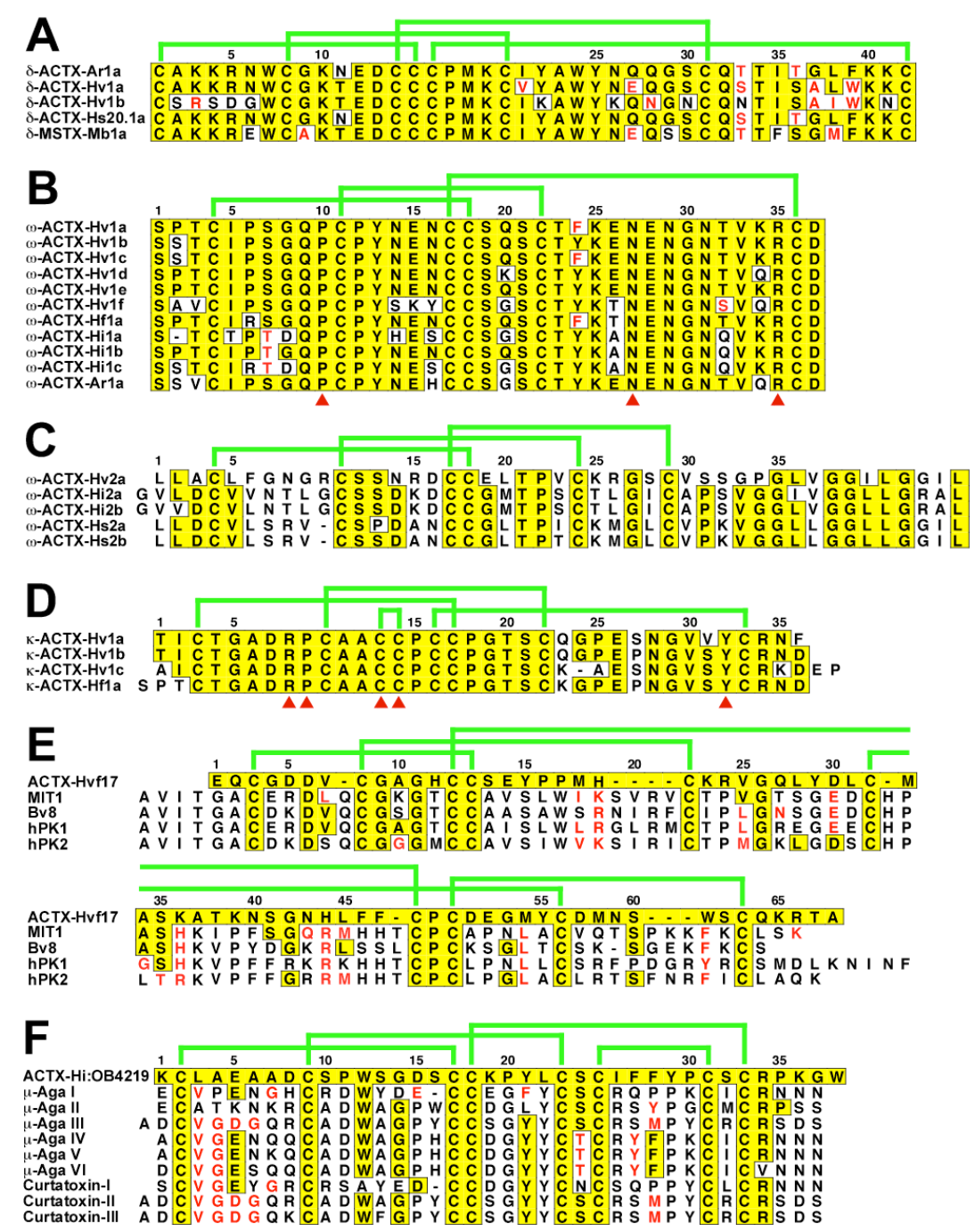

Fig. 4. Primary structures of atracotoxins. (A-F) Amino acid sequences showing identical residues boxed in grey and conservatively substituted residues in grey text. Where determined, disulfidebonding patterns for the cysteine residues are indicated above the sequences while key functional residues as determined by alanine-scanning mutagenesis are indicated by arrowheads below the

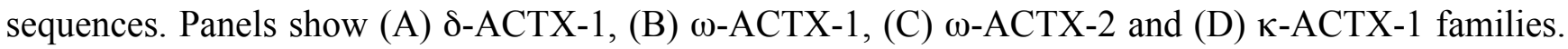
Included in (A) is the sequence of $\delta$-MSTX-Mb1a from the eastern mouse spider Missulena bradleyi. (E) Alignment of ACTX-Hvf17 with MIT1, Bv8 and selected members of the prokineticin family of proteins. (F) Alignment of ACTX-Hi:OB4219 with $\mu$-agatoxins and curtatoxins. Sequences were prepared using ALSCRIPT. 

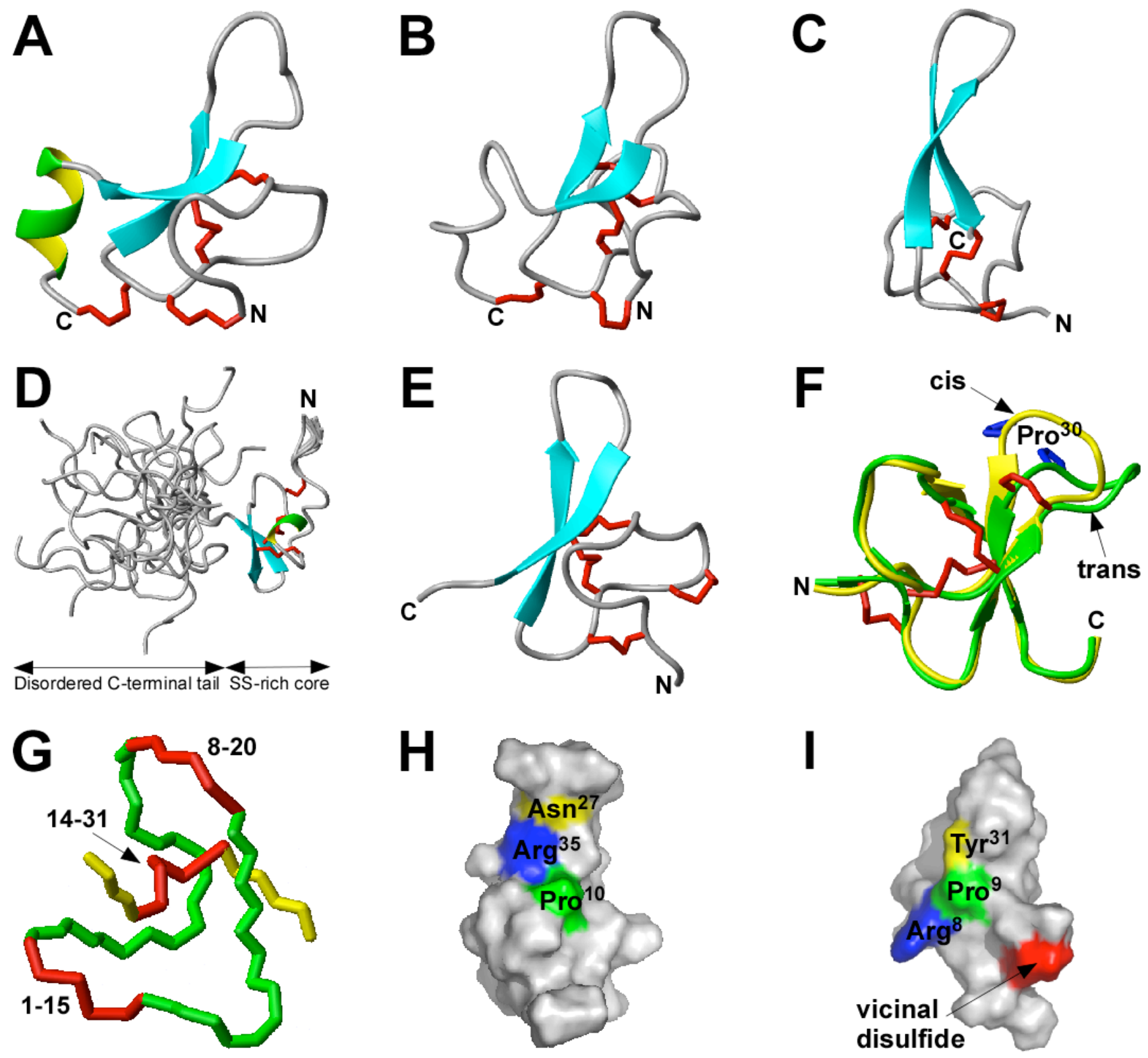

Fig. 5. Schematic views of atracotoxin solution structures. (A) $\delta$-ACTX-Hvla (PDB file 1VTX), (B)

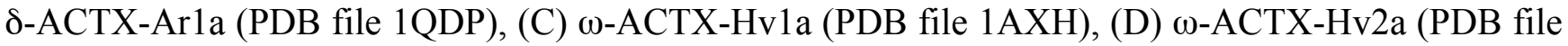
1G9P) and (E) א-ACTX-Hv1c (PDB file 1DLO) showing the location of $\beta$-strands (cyan arrows) and $3_{10}$-helix (green and yellow). (F) Schematic view of ACTX-Hi:OB4219 showing the cis (yellow; PDB file $1 \mathrm{KQH}$ ) and trans (green; PDB file 1KQI) conformations of the toxin. Cis/trans isomerism occurs at the bond preceding $\operatorname{Pro}^{30}$ (blue tubes). In all structures disulfides bridges form an inhibitor cystine-knot 
(ICK) motif and are shown as red tubes. Note: The solution structure for $\omega$-ACTX-Hv2a (D) represents an ensemble 10 structures showing the disordered C-terminal tail. (G) View of the ICK motif of

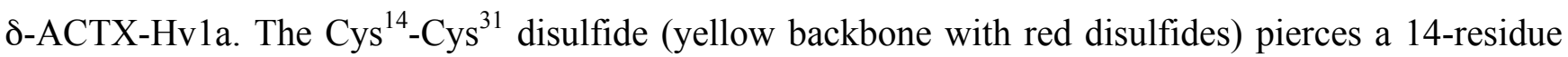
loop formed by the $\mathrm{Cys}^{1}-\mathrm{Cys}^{15}$ and $\mathrm{Cys}^{8}-\mathrm{Cys}^{20}$ disulfides (red) and the intervening sections of the backbone (green) to create a pseudo-knot. (H-I) Molecular surface representations indicating key residues involved in the insectophore of $\omega$-ACTX-Hvla (H) and $\kappa-A C T X-H v 1 c$ (I). Models were prepared using MOLMOL and PyMOL. 